\title{
Recent progress in Ti-based nanocomposite anodes for lithium ion batteries
}

\author{
Shitong WANG ${ }^{a, b, \dagger}$, Yong YANG ${ }^{c, \dagger}$, Yanhao $\mathrm{DONG}^{a}$, \\ Zhongtai ZHANG ${ }^{b}$, Zilong TANG ${ }^{b, *}$ \\ ${ }^{a}$ Department of Nuclear Science and Engineering, Massachusetts Institute of \\ Technology, Cambridge, Massachusetts 02139, USA \\ ${ }^{b}$ State Key Lab of New Ceramics and Fine Processing, School of Materials Science and \\ Engineering, Tsinghua University, Beijing 100084, China \\ ${ }^{c}$ Department of Materials Science \& Engineering, College of Engineering, \\ Peking University, Beijing 100871, China
}

Received: July 11, 2018; Accepted: July 23, 2018

(C) The Author(s) 2019.

\begin{abstract}
Studying on the anode materials with high energy densities for next-generation lithium-ion batteries (LIBs) is the key for the wide application for electrochemical energy storage devices. Ti-based compounds as promising anode materials are known for their outstanding high-rate capacity and cycling stability as well as improved safety over graphite. However, Ti-based materials still suffer from the low capacity, thus largely limiting their commercialized application. Here, we present an overview of the recent development of Ti-based anode materials in LIBs, and special emphasis is placed on capacity enhancement by rational design of hybrid nanocomposites with conversion-/ alloying-type anodes. This review is expected to provide a guidance for designing novel Ti-based materials for energy storage and conversion.
\end{abstract}

Keywords: lithium-ion batteries (LIBs); anode; titania; lithium titanate

\section{Introduction}

With the ever-increasing energy consumption/demand and environmental concerns, it is inevitable to develop sustainable and green-energy infrastructure. Lithium-ion batteries (LIBs) have been demonstrated a great success in electric vehicles (EVs) and portable electronic devices, which is arguably the most important energy storage and conversion technology [1]. Yet, the state-of-the-art LIBs still cannot catch up with the requirements of

$\dagger$ These authors contributed equally to this work.

* Corresponding author.

E-mail: tzl@tsinghua.edu.cn gravimetric/volumetric energy density, rate capability, cycling stability, safety, and cost in various applications. As one of the most promising anode materials for LIBs, Ti-based materials including $\mathrm{TiO}_{2}$ (TO) polymorphs and $\mathrm{Li}_{4} \mathrm{Ti}_{5} \mathrm{O}_{12}$ (LTO), have received considerable attention due to their superior cycling stability, rate performance, and safety compared to traditional graphite anode [2-4]. However, the major disadvantages that limit their use are poor electronic/ionic conductivity and relatively low gravimetric/volumetric energy density. To address the above issues, extensive researches have been conducted: (i) on the material level, to control the morphology, to dope the bulk material, and to modify the surface chemistry/structure [5-7]; (ii) on the system level, to 
hydride with other high-energy-density anodes, to increase the working voltage by using high-voltage cathodes, and to maximize the portion of active electrode materials [8]. However, the improvements are still limited, and new concepts are desperately required for further increasement in order to make Ti-based materials competitive with commercial anodes.

Depending on the reaction mechanism, one can classify electrode materials into three main types: insertion, conversion, and alloying. Graphite $(372 \mathrm{mAh} / \mathrm{g})$ and Ti-based anodes (e.g., anatase $\mathrm{TiO}_{2}: 335 \mathrm{mAh} / \mathrm{g} ; \mathrm{Li}_{4} \mathrm{Ti}_{5} \mathrm{O}_{12}$ : $263 \mathrm{mAh} / \mathrm{g}$ ) are the classical examples of insertion reaction, demonstrating excellent cycling stability. However, their capacities are usually lower compared with the other two types. Conversion-type anodes include many transitional metal oxides/sulfides such as $\mathrm{MoO}_{2}$ (830 mAh/g), $\mathrm{MoS}_{2}(670 \mathrm{mAh} / \mathrm{g}), \mathrm{Co}_{3} \mathrm{O}_{4}(890 \mathrm{mAh} / \mathrm{g})$, $\mathrm{MnO}_{x}(700-1000 \mathrm{mAh} / \mathrm{g}), \mathrm{Fe}_{2} \mathrm{O}_{3}(1008 \mathrm{mAh} / \mathrm{g}), \mathrm{Fe}_{3} \mathrm{O}_{4}$ (926 mAh/g), FeS (610 mAh/g), and $\mathrm{CuO}(674 \mathrm{mAh} / \mathrm{g})$; and alloying-type anodes include $\mathrm{Si}$ (3579 $\mathrm{mAh} / \mathrm{g}), \mathrm{Sn}$ (993 $\mathrm{mAh} / \mathrm{g}$ ), and Al (2234 mAh/g) [9-12]. Their capacities are much higher than that from insertion reaction, yet the huge volume changes during charge/ discharge lead to severe microstructural instability, resulting in pulverization and hence very poor cyclability. This Achilles' heel of conversion-/alloying-type anodes has been tentatively solved by nano-structuring, where stresses generated from the volume change can be partially released by the large surface area, thus structural failure can be greatly deferred. However, aggregation of nano-particles often occurs during the material synthesis, electrode preparation, and electrochemical cycling, and makes it less useful in practical applications. Therefore, it has been proposed to hybrid insertion-type anodes with conversion-/alloying-type ones and assemble their nanocomposites, to achieve high capacity from conversion-/alloying-type components, high stability by insertion-type components and their buffering effect (to release stresses from conversion-/alloying-type reactions), and high rate performance from nano-structuring. This strategy has been employed to develop graphite/Si composites, with many research papers and reviews available in the literatures [11-14].

Here we shall summary an updated review regarding Ti-based system materials in LIBs. Its great potential is rooted in the much better cycling life of Ti-based materials $\left(10^{3}-10^{4}\right.$ cycles $)$ over traditional graphite $\left(10^{2}-10^{3}\right.$ cycles). The focus shall be given on the synergistic effect (Fig. 1) from highly stable Ti-based

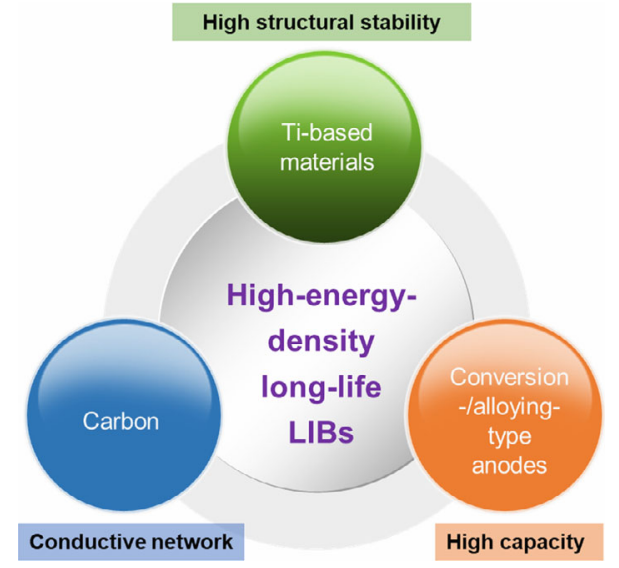

Fig. 1 Schematic illustration of capacity enhancement protocol for Ti-based materials.

substrate and high-capacity conversion-/alloying-type anodes, together with conductive carbon which provides not only a percolating electron network but also many other benefits as will be discussed later. We argue a rational design of such heterogeneous nanostructures, rather than simplified physical mixtures, is the key to achieve high electrochemical performance, which is rarely reviewed comprehensively. We shall briefly review Ti-based materials in Section 2 and then emphasize on the recent development of their hybrid nanoachitectures with conversion-/alloying-type anodes in Section 3, followed by discussions and future perspectives in Section 4 .

\section{Ti-based materials}

Ti-based anode materials have attracted much attention in LIBs due to negligible volume changes during charge/ discharge and hence superior cycling stability, and lots of Ti-based materials have been prepared and reviewed [2,3,5-8,15-17]. In this subsection, recent progresses in $\mathrm{TiO}_{2}$ polymorphs and $\mathrm{Li}_{4} \mathrm{Ti}_{5} \mathrm{O}_{12}$ and common practices to improve their electrochemical performances will be reviewed, including nano-structuring, carbon coating/ decoration, and hierarchical micro-/nano-structure assembly.

\section{2. $1 \mathrm{TiO}_{2}$}

Owing to their excellent cycle stability, high operating voltage $\left(1.3-1.8 \mathrm{~V}\right.$ vs. $\left.\mathrm{Li} / \mathrm{Li}^{+}\right)$, low cost, and environmentally friendly advantages, $\mathrm{TiO}_{2}$ has been regarded as a promising insertion-type anode in LIBs. Although lithium intercalation numbers are varied with different 
crystal structures of $\mathrm{TiO}_{2}$ (such as anatase $\mathrm{TiO}_{2}$, rutile $\mathrm{TiO}_{2}$, and $\mathrm{TiO}_{2}(\mathrm{~B})$ ), similar electrochemical reactions can be summarized as follows: $\mathrm{TiO}_{2}+x \mathrm{Li}^{+}+x \mathrm{e}^{-} \Leftrightarrow$ $\mathrm{Li}_{x} \mathrm{TiO}_{2}(0<x \leqslant 1)$. It is worth mentioning that the crystal structure, particle size, and morphology of $\mathrm{TiO}_{2}$ material would greatly influence the variate $x$ in the above equation. When $x=1, \mathrm{TiO}_{2}$ can offer a theoretical specific capacity up to $335 \mathrm{mAh} / \mathrm{g}$. However, the low electron and ion conductivities limit the specific capacity of $\mathrm{TiO}_{2}$. Rational designing nanostructures, coupled with conductive carbon materials or metal oxides, and element doping, the electrochemical performance of $\mathrm{TiO}_{2}$ can be effectively improved $[2,3,17,18]$.

Among the various $\mathrm{TiO}_{2}$ polymorphs, $\mathrm{TiO}_{2}(\mathrm{~B})$ possesses a favorable open channel structure and unique electrochemical mechanism for lithium storage, which can provide fast charging-discharging capability of the electrode. What is more, it can accommodate more $\mathrm{Li}$ ions compared to other $\mathrm{TiO}_{2}$ polymorphs, endowing large theoretical specific capacity of $335 \mathrm{mAh} / \mathrm{g}$. The lithium storage mechanism of $\mathrm{TiO}_{2}(\mathrm{~B})$ contains the mixed pseudocapacitive faradic process and diffusion limited solid-state reaction process [19]; therefore, there usually shows an obvious electrochemical performances enhancement when increasing the specific surface area via various nanostructures. $\mathrm{Li}$ et al. [20] reported $\mathrm{TiO}_{2}(\mathrm{~B})$ nanowires using hydrothermal reaction of $\mathrm{P} 25$ in $\mathrm{KOH}$ solution and subsequent hydrothermal transferring of the proton exchanged K-titanate precursors into $\mathrm{TiO}_{2}(\mathrm{~B})$ in acid solution, which avoids the process of hightemperature treatment. Due to the ultrahigh surface area of $210 \mathrm{~m}^{2} / \mathrm{g}$, the obtained $\mathrm{TiO}_{2}$ (B) can accommodate $1.15 \mathrm{~mol} \mathrm{Li}$ ions (specific capacity: $388 \mathrm{mAh} / \mathrm{g}$ ) per mole $\mathrm{TiO}_{2}$. Liu et al. [21] synthesized $\mathrm{TiO}_{2}(\mathrm{~B})$ with mesoporous structure and microsphere morphology (Fig. 2(a)), which facilitates fast $\mathrm{Li}^{+}$ion transport and the contact between electrode and electrolyte. As a result, the electrode exhibited excellent high-rate cycling performances at $10 \mathrm{C}$ for 5000 cycles, with a capacity loss of $0.002 \%$ per cycle. Later, Tang et al. [22] developed a mechanical force-driven hydrothemal method for threedimensional (3D) cross-linked network with elongated bending $\mathrm{TiO}_{2}(\mathrm{~B})$ nanotubes. The as-synthesized $\mathrm{TiO}_{2}(\mathrm{~B})$ electrode exhibits outstanding cycling stability at high rate of $25 \mathrm{C}$ for more than 10,000 cycles with $0.0003 \%$ capacity fading per cycle. They also investigate the relationship between the nanotubular aspect ratio and electrochemical performance, and they found that the electronic/ionic transport kinetic dramatically increases with the rising of aspect ratio (Figs. 2(b) and 2(c)) [23]. In addition to the nanostructuring method, combining with some conductive materials (such as carbon series materials) is also a common and effective technology to improve the electrochemical performance, owing to enhanced movement of ions and electrons, high structural stability, and mechanical flexibility. Liu et al. [24] reported an additive-free flexible film electrode composed of $\mathrm{TiO}_{2}(\mathrm{~B})$ nanosheets on non-woven activated carbon nanofibers, leading to remarkable high-rate cycling stability for more than 2000 cycles with $0.0007 \%$ capacity fading per cycle. Similarly, Ren et al. [25] developed an edge-oriented multilayer graphene (EOG) foam to load $\mathrm{TiO}_{2}$ (B) nanosheets, which exhibited 12,000 stable cycling at $8 \mathrm{C}$ rate with only $0.002 \%$ capacity decay per cycle.

Other $\mathrm{TiO}_{2}$ polymorphs such as anatase $\mathrm{TiO}_{2}$ and rutile $\mathrm{TiO}_{2}$ have also been intensively studied owing to their outstanding structural stability during electrochemical reactions. Nanostructuring is the common method for the electrochemical performances enhancement. Guan et al. [26] exhibited a series of hollow, core-shell, and yolk-shell $\mathrm{TiO}_{2}$ nanoshells which can be formed on various silica-based, metal, metal oxide, organic polymer, carbon-based, and metal-organic framework nanomaterials (Figs. 2(d)-2(f)). Due to the tiny nanocrystals in the nanoshells, these $\mathrm{TiO}_{2}$ nanoachitectures illustrated improved rate capacity and cycling stability. Wei et al. [27] prepared a mesoporous yolk-shell spherical nanostructures composed of anatase $\mathrm{TiO}_{2}$ (as a core) and $\mathrm{TiO}_{2}$ (B) (as a shell), which demonstrated outstanding high-rate capability of $181.8 \mathrm{mAh} / \mathrm{g}$ at 40 $\mathrm{C}$ and excellent cycling stability for 500 cycles with only $0.004 \%$ capacity loss per cycle (Fig. 2 (g)). The improved rate capability can be ascribed to the extra space between the core and shell which is useful for pseudocapacity contribution and volume-swell/shrink accommodation. What is more, black $\mathrm{TiO}_{2}$ nanoparticles ( $81 \%$ anatase and $19 \%$ rutile phases) with a narrow bandgap (only $1.85 \mathrm{eV}$ ) were obtained through precursor heating under $\mathrm{H}_{2}$ stream, followed by fast cooling in inert environment until room temperature [28]. Due to the surface disorder and oxygen vacancy, the electronic conductivity can be greatly improved. The electrochemical performance of black $\mathrm{TiO}_{2}$ was reported by Xia et al. Owing to the enhanced ion exchange and movement in the hydrogenated disordered surface, the specific capacity and cyclability have been obviously improved [29]. For the electrochemical 


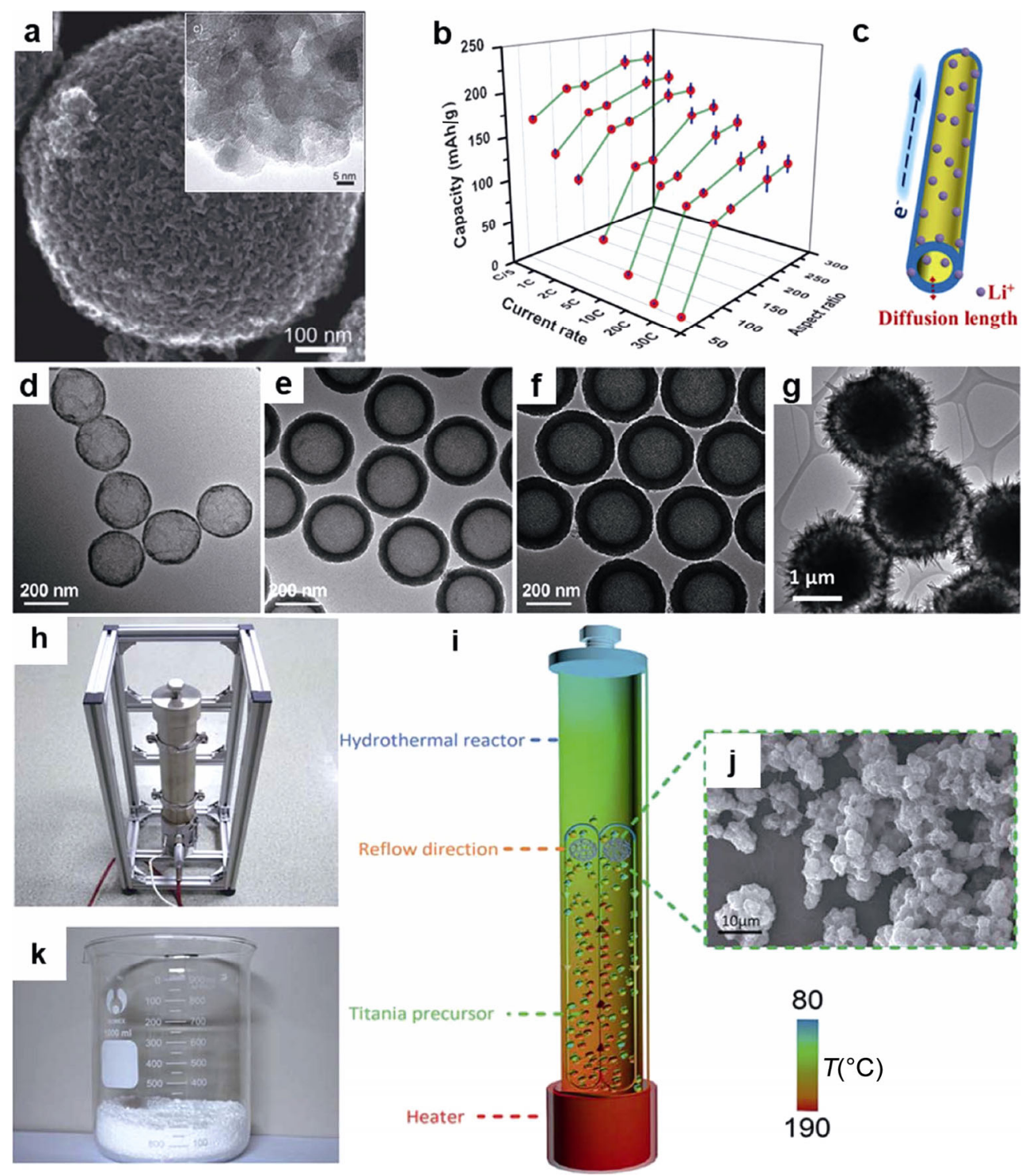

Fig. 2 Recent progress of $\mathrm{TiO}_{2}$ materials. (a) TEM images of mesoporous $\mathrm{TiO}_{2}(\mathrm{~B})$ microspheres with porous and hollow structure. Reproduced with permission from Ref. [21], (C) John Wiley and Sons 2011. (b) Relationship between the aspect ratio and the capacity of different nanotubes and (c) scheme of the electron and $\mathrm{Li}^{+}$transport pathways. Reproduced with permission from Ref. [23], (C) John Wiley and Sons 2014. $\mathrm{TiO}_{2}$ hollow spheres with varied shell thicknesses: (d) $8 \mathrm{~nm}$, (e) $41 \mathrm{~nm}$, and (f) 54 $\mathrm{nm}$. Reproduced with permission from Ref. [26], (C) AAAS 2016. (g) TEM image of mesoporous yolk-shell anatase $\mathrm{TiO}_{2} / \mathrm{TiO}_{2}(\mathrm{~B})$ microspheres. Reproduced with permission from Ref. [27], (C) John Wiley and Sons 2017. (h) Real photo of the thermal-convection hydrothermal apparatus, (i) schematic diagram of the formation process of $\mathrm{TiO}_{2}$ microclews, and (j) SEM image and (k) digital photograph of the obtained products. Reproduced with permission from Ref. [31], (C) The Royal Society of Chemistry 2018.

performance improvement by various carbon modifications, mesoporous hollow anatase $\mathrm{TiO}_{2} /$ graphitic carbon spheres [30], $\mathrm{TiO}_{2}$ microclews (obtained by a self-made thermal-convection hydrothermal equipment, Figs. 2(h) $-2(\mathrm{k})$ ) on a carbon cloth with high mass loading density up to $4 \mathrm{mg} / \mathrm{cm}^{2}$ [31], ultrafine $\mathrm{TiO}_{2}$ nanocrystals $(6 \mathrm{~nm})$ with the binder-free porous $(50 \mu \mathrm{m})$ graphene (PG) network foam [32], amorphous $\mathrm{TiO}_{2}$ on carbon nanotube network [33] can deliver a capacity of
$137 \mathrm{mAh} / \mathrm{g}$ up to 1000 cycles at $\sim 5 \mathrm{C}(0.008 \%$ capacity fading per cycle); a capacity of $74 \mathrm{mAh} / \mathrm{g}$ up to 1000 cycles at $2000 \mathrm{~mA} / \mathrm{g}(0.033 \%$ capacity fading per cycle); a capacity of $\sim 60 \mathrm{mAh} / \mathrm{g}$ up to 10,000 cycles at $15,300 \mathrm{~mA} / \mathrm{g}(0.0002 \%$ capacity fading per cycle); a capacity of $120 \mathrm{mAh} / \mathrm{g}$ up to 10,000 cycles at 2000 $\mathrm{mA} / \mathrm{g}(0.0007 \%$ capacity fading per cycle), respectively. The remarkable excellent high rate capability of the above nanocomposites could be attributed to (i) high 
specific surface area and large pore volume of $\mathrm{TiO}_{2}$ nanomaterials, (ii) enhanced ionic diffusivity and the electronic conductivity as well as (iii) the nanomaterial aggregation prevention and structure change alleviation by conductive carbon networks (especially twodimensional (2D) graphene, one-dimensional (1D) carbon nanotubes (CNTs), and carbon nanofibers) [34,35]. To sum up, by using various nanostructures and carbon modification, $\mathrm{TiO}_{2}$ can exhibit excellent cyclability of about $10^{3}-10^{4}$ cycles with $<10^{-3} \%$ capacity loss per cycle, demonstrating a quite stable structure during fast insertion/extraction of $\mathrm{Li}^{+}$ions.

\section{2. $2 \quad \mathrm{Li}_{4} \mathrm{Ti}_{5} \mathrm{O}_{12}$}

Spinel $\mathrm{Li}_{4} \mathrm{Ti}_{5} \mathrm{O}_{12}$ is considered to be the most promising anode in real-life application for LIBs. During the discharging process, $3 \mathrm{~mol} \mathrm{Li}^{+}$ions will insert into $1 \mathrm{~mol}$ spinel $\mathrm{Li}_{4} \mathrm{Ti}_{5} \mathrm{O}_{12}$ structure to form a rack salt structure $\mathrm{Li}_{7} \mathrm{Ti}_{5} \mathrm{O}_{12}$ first, resulting in the voltage decrease to $1.0 \mathrm{~V}$ (vs. $\mathrm{Li} / \mathrm{Li}^{+}$). At the same time, $\sim 60 \% \mathrm{Ti}^{4+}$ in $\mathrm{Li}_{4} \mathrm{Ti}_{5} \mathrm{O}_{12}$ are reduced to $\mathrm{Ti}^{3+}$ (Eq. (1)). Then the specific capacity of $\mathrm{Li}_{4} \mathrm{Ti}_{5} \mathrm{O}_{12}$ can be calculated as $175 \mathrm{mAh} / \mathrm{g}$, and the phase transformation exhibits a flat voltage plateau at $\sim 1.55 \mathrm{~V}$ (vs. $\mathrm{Li} / \mathrm{Li}^{+}$). The subsequent lithiation process will lead to further reduction reaction for the rest $\mathrm{Ti}^{4+}$. Based on the first-principle calculations, the final composition of fully-lithiated $\mathrm{Li}_{4} \mathrm{Ti}_{5} \mathrm{O}_{12}$ is supposed to be $\mathrm{Li}_{8.5} \mathrm{Ti}_{5} \mathrm{O}_{12}$, delivering the theoretical specific capacity of $263 \mathrm{mAh} / \mathrm{g}$ (Eq. (2)) [36]. It should be noted that the phase transformation from the spinel $\mathrm{Li}_{4} \mathrm{Ti}_{5} \mathrm{O}_{12}$ to rock salt $\mathrm{Li}_{7} \mathrm{Ti}_{5} \mathrm{O}_{12}$ results in only $0.2 \%$ change in the cell volume [37], and even at the fully lithiated state about $0 \mathrm{~V}$ (vs. $\mathrm{Li} / \mathrm{Li}^{+}$), the volume expansion of $\mathrm{Li}_{8.5} \mathrm{Ti}_{5} \mathrm{O}_{12}$ was only $0.4 \%$ based on the theoretical calculations. Therefore, the zero-strain $\mathrm{Li}_{4} \mathrm{Ti}_{5} \mathrm{O}_{12}$ is widely considered as an ideal electrode that can possess extremely long cycle life because tiny lattice changes not only remain the crystal structure stable in each lithiation/delithiation process but also maintain the mechanical integrity of the binder and conductive carbon matrix which are quite crucial for electron conducting pathway during long-term cycling. However, relatively poor electronic conductivity $\left(10^{-13}-10^{-8} \mathrm{~S} / \mathrm{cm}\right)$ [5] and low $\mathrm{Li}^{+}$ion diffusion coefficient (ca. $10^{-16}-10^{-9} \mathrm{~cm}^{2} / \mathrm{s}$ ) $[6,8]$ of $\mathrm{Li}_{4} \mathrm{Ti}_{5} \mathrm{O}_{12}$ are the most crucial problems, impeding the capacity release at high current densities.

$$
\begin{gathered}
\mathrm{Li}_{4} \mathrm{Ti}_{5} \mathrm{O}_{12}+3 \mathrm{Li}^{+}+3 \mathrm{e}^{-} \Leftrightarrow \\
\mathrm{Li}_{7} \mathrm{Ti}_{5} \mathrm{O}_{12}\left(1.0-3.0 \mathrm{~V} \text { vs. } \mathrm{Li} / \mathrm{Li}^{+}\right)
\end{gathered}
$$

$$
\begin{gathered}
\mathrm{Li}_{4} \mathrm{Ti}_{5} \mathrm{O}_{12}+4.5 \mathrm{Li}^{+}+4.5 \mathrm{e}^{-} \Leftrightarrow \\
\mathrm{Li}_{8.5} \mathrm{Ti}_{5} \mathrm{O}_{12}\left(0.05-3.0 \mathrm{Vvs.} \mathrm{Li} / \mathrm{Li}^{+}\right)
\end{gathered}
$$

To date, different nanostructured $\mathrm{Li}_{4} \mathrm{Ti}_{5} \mathrm{O}_{12}$ including nanoparticle, nanowire, nanotube, nanofiber, and 2D nanosheet and nanoplate, 3D hierarchical nanostructure, and other hybrid architectures have been successfully prepared and displayed. Ordered large-pore mesoporous $\mathrm{Li}_{4} \mathrm{Ti}_{5} \mathrm{O}_{12}$ thin film electrodes with nanocrystalline framework exhibited cycling stability for 3000 cycles at $64 \mathrm{C}$ with capacity from 155 to $148 \mathrm{mAh} / \mathrm{g}(0.002 \%$ capacity loss per cycle) [38]. A hierarchical structure assembled by $\mathrm{Li}_{4} \mathrm{Ti}_{5} \mathrm{O}_{12}$ ultrathin nanosheets (with large specific surface area of $178 \mathrm{~m}^{2} / \mathrm{g}$ ) shows excellent cycling performances for 3000 cycles at $20 \mathrm{C}$ with $0.008 \%$ capacity loss per cycle [39]. However, the large specific surface area of nanostructured materials compromises the tap density of electrodes, which decreases the volumetric energy density of the full cells. Besides, due to the large electrochemical active specific area contacted with electrolyte, more side reactions would happen, which will consume much Li from the cathode forming lead lithium. Introducing grain boundaries and phase interfaces have provided to solve the problem. It was acknowledged that the presence of enormous grain boundaries and phase interfaces not only can provide more $\mathrm{Li}^{+}$storage sites, but also accelerate lithium ion and electron transportation. Wang et al. [40] synthesized densely packed $\mathrm{Li}_{4} \mathrm{Ti}_{5} \mathrm{O}_{12}$ submicrospheres with enhanced high tap density $\left(1.2 \mathrm{~g} / \mathrm{cm}^{3}\right)$ and relatively low surface area $\left(8.6 \mathrm{~m}^{2} / \mathrm{g}\right)$. Benefiting from the abundant grain boundaries between the nanocrystallites in the submicron spheres, the columbic efficiency of the first cycle is high as $96.13 \%$ and the electrode shows good capacity retention ratio of $97.3 \%$ after 500 cycles at $10 \mathrm{C}$. Except for the grain boundaries between the nanocrystallites of one single phase, dual-phase composites usually give more grain boundaries due to abundant phase interfaces, which can be demonstrated by the capacity and ionic transport improvement of $\mathrm{Li}_{4} \mathrm{Ti}_{5} \mathrm{O}_{12} /$ $\mathrm{TiO}_{2}$ multilayer arrays $(147.6 \mathrm{mAh} / \mathrm{g}$ at $30 \mathrm{C})$ compared with $\mathrm{Li}_{4} \mathrm{Ti}_{5} \mathrm{O}_{12}$ arrays $(92.1 \mathrm{mAh} / \mathrm{g}$ at $30 \mathrm{C})$ [41]. Recently, our group developed a partial lithiation reaction and optimized heat treatment method to fabricate triplephase $\mathrm{Li}_{4} \mathrm{Ti}_{5} \mathrm{O}_{12} / \mathrm{TiO}_{2}$ (anatase) $/ \mathrm{TiO}_{2}$ (rutile) nanoplates (Figs. 3(a) and 3(b)). Note that partial anatase $\mathrm{TiO}_{2}$ converted into rutile $\mathrm{TiO}_{2}$ will further increase phase boundary density. A capacity of about $139 \mathrm{mAh} / \mathrm{g}$ can be still maintained after 1000 cycles even at high current 


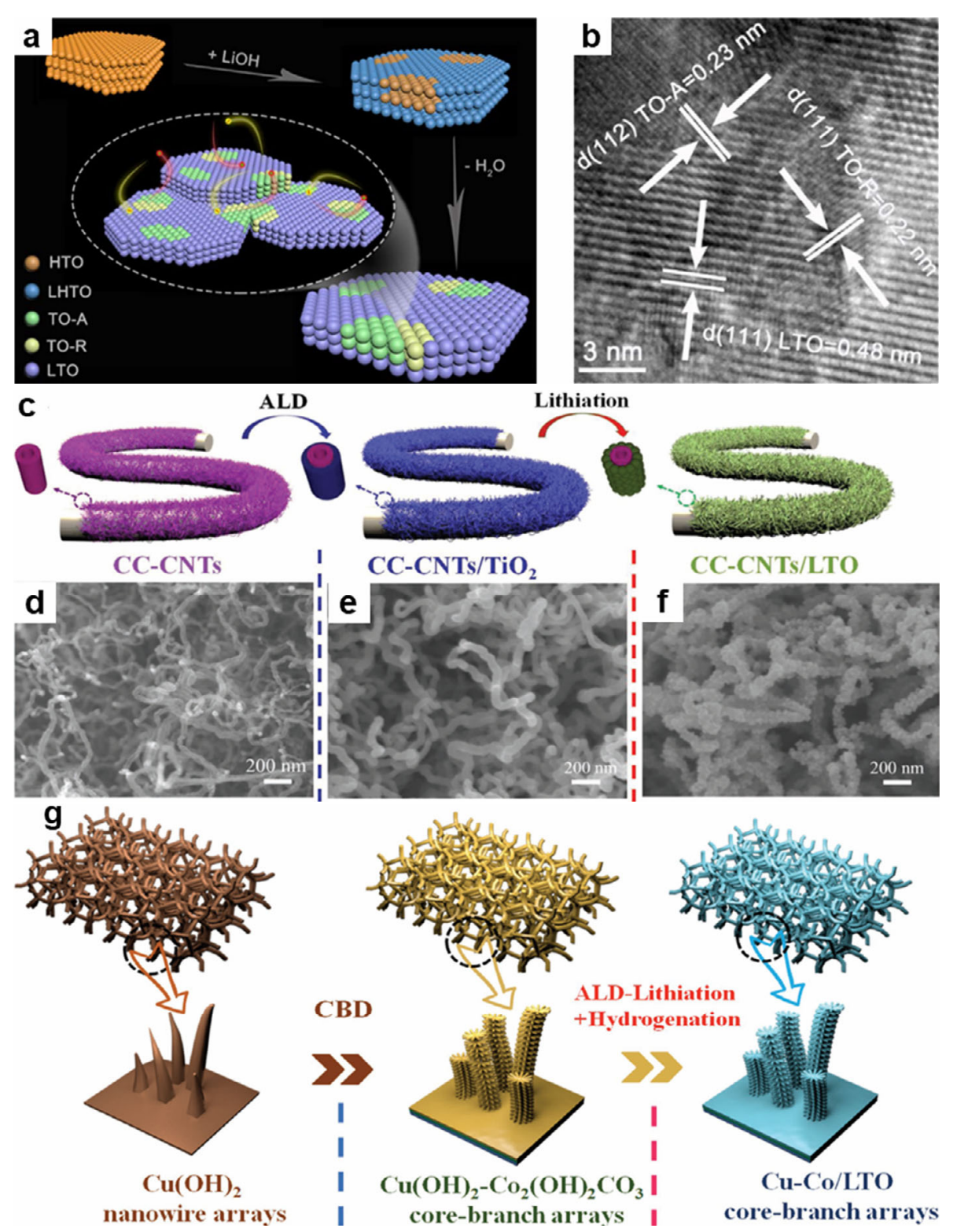

Fig. 3 Recent progress of $\mathrm{Li}_{4} \mathrm{Ti}_{5} \mathrm{O}_{12}$ materials. (a) Schematic diagram and (b) HRTEM image of the synthesis procedure of $\mathrm{Li}_{4} \mathrm{Ti}_{5} \mathrm{O}_{12}$ /anatase $\mathrm{TiO}_{2} /$ rutile $\mathrm{TiO}_{2}$. Reproduced with permission from Ref. [42], (C) Elsevier Ltd. 2017. (c) Schematics and (d-f) SEM images of the synthesis procedure of carbon cloth (CC)-CNTs $/ \mathrm{Li}_{4} \mathrm{Ti}_{5} \mathrm{O}_{12}$ arrays. Reproduced with permission from Ref. [44], (C) John Wiley and Sons 2018. (g) Illustration of synthesis of $\mathrm{Cu}-\mathrm{Co} / \mathrm{Li}_{4} \mathrm{Ti}_{5} \mathrm{O}_{12}$ core-branch arrays. Reproduced with permission from Ref. [47], (C) John Wiley and Sons 2018.

density of $4000 \mathrm{~mA} / \mathrm{g}$ (with $0.02 \%$ capacity fading per cycle) [42]. It was believed that such a multiphase composite designed strategy could be employed as a new way to improve conductivity, tap density, and Coulombic efficiency of one electrode, rather than using excessively large free surface or relying $\mathrm{Ti}^{3+}$ defects.

Just as $\mathrm{TiO}_{2}$, various $\mathrm{Li}_{4} \mathrm{Ti}_{5} \mathrm{O}_{12}$-based carbon hybrids have also been designed to improve the cyclability and reversible capacity of $\mathrm{Li}_{4} \mathrm{Ti}_{5} \mathrm{O}_{12}$, which include $\mathrm{Li}_{4} \mathrm{Ti}_{5} \mathrm{O}_{12}$ with mesoporous carbon matrix (1000 cycles with $0.006 \%$ capacity loss per cycle at $20 \mathrm{C}$ ) [43], CNTs/
$\mathrm{Li}_{4} \mathrm{Ti}_{5} \mathrm{O}_{12}$ core/shell arrays on carbon cloth $(5000$ cycles with $0.003 \%$ capacity loss per cycle at $10 \mathrm{C}$, Figs. 3(c)-3(f)) [44], conductive ink based $\mathrm{Li}_{4} \mathrm{Ti}_{5} \mathrm{O}_{12} /$ RGO (1000 cycles with $0.005 \%$ capacity loss per cycle at 90 C) [45]. Besides carbon modification, Wang et al. [46] synthesized well-defined $\mathrm{Li}_{4} \mathrm{Ti}_{5} \mathrm{O}_{12}$ nanosheets terminated with rutile- $\mathrm{TiO}_{2}$ at the edges, demonstrating the utility of rutile- $\mathrm{TiO}_{2}$ as a carbon-free coating layer to improve the charge transfer reaction and the lithium diffusion coefficient. Recently, Zhou et al. [47] used $\mathrm{Cu}-\mathrm{Co}$ mental arrays as the conductive skeleton to support 
highly active $\mathrm{Li}_{4} \mathrm{Ti}_{5} \mathrm{O}_{12}$ shell, forming a core-branch pine-needle-like hetero-nanostructure (Fig. 3(g)). Taking the advantages of large porosity, high conductivity, and enhanced adhesion, the nanoarchitectures exhibited remarkable high-rate capacity of $155 \mathrm{mAh} / \mathrm{g}$ at $20 \mathrm{C}$ and outstanding cyclability for more than 3000 cycles $(144 \mathrm{mAh} / \mathrm{g})$ at $20 \mathrm{C}$ with $0.003 \%$ capacity loss per cycle. As a consequence, by using various nanostructures and carbon modification, the capacity of $\mathrm{Li}_{4} \mathrm{Ti}_{5} \mathrm{O}_{12}$ at high rate $(10-90 \mathrm{C})$ is quite stable for thousands of cycles, implying it an ideal host for rapid $\mathrm{Li}^{+}$ion transportation and storage during lithiation/delithiation.

As mentioned above, relatively low theoretical specific capacity is the biggest problem for insertion-type materials (Fig. 4). $\mathrm{Li}_{4} \mathrm{Ti}_{5} \mathrm{O}_{12}$ and $\mathrm{TiO}_{2}$ polymorphs are no exception $\left(\mathrm{Li}_{4} \mathrm{Ti}_{5} \mathrm{O}_{12}: 175 \mathrm{mAh} / \mathrm{g} ; \mathrm{TiO}_{2}: 335 \mathrm{mAh} / \mathrm{g}\right)$. However, numerous works we mentioned in this section demonstrate that the most impressive feature for Ti-based materials is their outstanding capacity retention even after ultralong high-rate cycle life, which makes it possible as a robust substrate material for long-term cycling performance.

\section{Ti-based hybrid nanocomposite with conversion-/alloying-type anodes}

As is clear from Section 2, Ti-based anodes have superior stability and excellent cycling life yet, its capacity is relatively low. Therefore, it has been proposed to hybrid them with some high-capacity conversion-/alloying-type anodes. As one of the most popular research interests in the energy storage field nowadays, alloying-type materials can possess tremendous theoretical specific capacity, good safety, and quite low working potentials versus lithium compared with other intercalation-type (except for the graphite material) and conversion-type materials [12]. Electrochemically alloying and dealloying reactions can happen between lithium and a number of metallic and semi-metallic elements (Fig. 4), such as $\mathrm{Si}$, $\mathrm{Sn}, \mathrm{Ge}, \mathrm{Pb}, \mathrm{Sb}, \mathrm{Al}, \mathrm{Mg}$, as well as some metal oxides such as $\mathrm{SnO}_{x}, \mathrm{ZnO}, \mathrm{SnO}_{2}, \mathrm{Sb}_{2} \mathrm{O}_{3}$, and $\mathrm{ZnFe}_{2} \mathrm{O}_{4}$. The above binary or ternary component materials usually undergo conversion reactions at higher potentials and alloying/dealloying reactions at lower potentials, exhibiting similar theoretical specific capacity as the metal elements. A large number of research articles and review articles have summarized these materials in detail $[9-14,48]$. Moreover, several companies such as Panasonic Corp., Samsung SDI, Amprius, Inc., LG Chem., have already commercialized such electrode materials in the lithium ion batteries. However, most alloying-type anode materials suffer from irreversible structural changes and very poor cyclability, which could be due to the large volume change during charge/ discharge, the formation/decomposition of unstable solid-electrolyte interface (SEI), the trapping of lithium in the host alloy, the reaction with oxide impurities, and

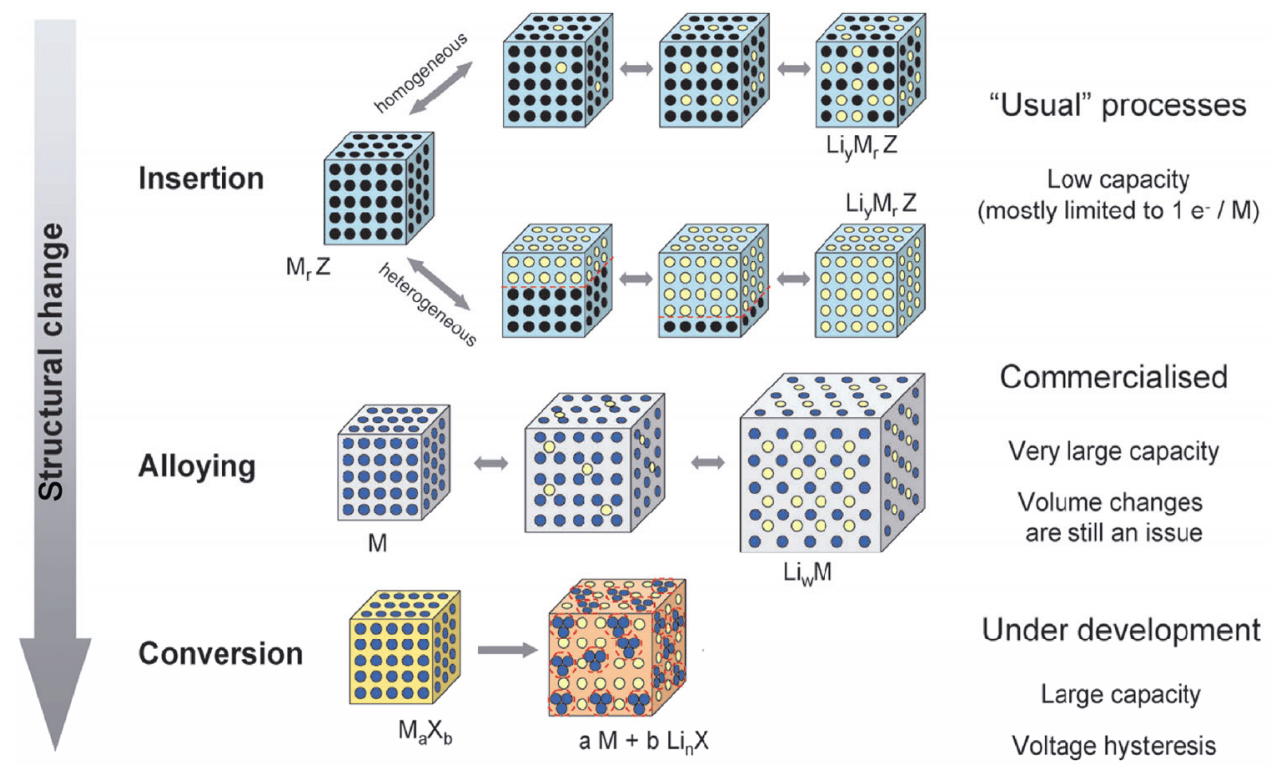

Fig. 4 Schematic representation of insertion-, alloying-, and conversion-type electrodes for LIBs. Black circles: voids in the crystal structure; blue circles: metal; yellow circles: lithium. Reproduced with permission from Ref. [56], (C) The Royal Society of Chemistry 2009. 
the aggregation of alloy nanoparticles. Many efforts have been spent to solve the problems, including surface coating, multiphase composites, reducing particle size, cycling-voltage control, binder, and electrolyte design $[11,14]$.

Different from the insertion- or alloying-type materials mentioned above, conversion-type materials usually involve a reversible electrochemical reaction between $\mathrm{M}_{x} \mathrm{~N}_{y}(\mathrm{M}=\mathrm{Co}, \mathrm{Mn}, \mathrm{Ni}, \mathrm{Mo}, \mathrm{Cu}, \mathrm{Fe}, \mathrm{Cr}, \mathrm{Ru}$, etc.; $\mathrm{N}=$ $\mathrm{O}, \mathrm{S}, \mathrm{P}, \mathrm{F}, \mathrm{Cl}$, etc.) and metal $\mathrm{M}^{0}$ nanoparticles embedded in a matrix of $\mathrm{Li}_{y} \mathrm{~N}[9,12]$ as illustrated in Fig. 4. As the electrochemical process is associated with the multiple electronic redox reactions between transition metal with high valence state and its zero metallic state, it can exhibit a considerably high specific capacity. Accompanying conversion reaction of their composites, formation of the SEI layer by electrolyte decomposition and the large volume variation during the phase transition results in a huge irreversible capacity loss during first several cycles and poor cycleability. In order to circumvent the above problems, nanoachitecture design, such as 1D nanotubes (wires), 2D nanosheets, 3D micro-nano spheres (hollow structure) can not only effectively reduce the volume change during the conversion reaction, but also can reduce the $\mathrm{Li}^{+}$ diffusion pathway; thereby, the rate performance and cycling stability have been greatly enhanced [49-53]. In addition, by coating or compositing with conductive carbon materials, metals, conductive polymers can effectively suppress the agglomeration and pulverization of the active material and increase the electrical contact and mechanical integrity of the electrode $[9,54,55]$, hence leading to the high specific capacity and long-term stability.

\section{1 Conversion-type hybrid nanocomposites}

To enhance the capacity, various high-capacity materials were introduced into host electrode materials. In this section, the conversion-type electrochemical properties of the Ti-based hybrid composite and their performance as anodes in LIBs will be briefly discussed.

First, we will take $\mathrm{TiO}_{2}$ as an example. 1D $\mathrm{TiO}_{2}$ nanostructure is featured with superior conductivity and low volume expansion, which makes it possible to serve as the backbone of hybrid structures. Recently, our group developed a novel hybrid composed of $\mathrm{TiO}_{2}$ nanowires decorated with $\mathrm{MoO}_{2}$ quantum dots encapsulated in carbon nanosheets via a simple polymerization method and heat treatment as illustrated in Fig. 5(a) [57]. In a typical synthesis, hydrogen titanate (HTO) nanowires were initially obtained by a simple hydrothermal method. Then, Mo-polydopamine nanosheets can be successfully grown on the surface of HTO nanowires via a polymerization reaction under weakly alkaline solution. After heat treatment as prepared HTO@Mo-PDA hybrid precursor in a $\mathrm{N}_{2}$ atmosphere, the core HTO nanowire transformed to $\mathrm{TiO}_{2}$, and the external Mo-PDA nanosheets in situ converted to tiny $\mathrm{MoO}_{2}$ nanoparticles (about $1 \mathrm{~nm}$ ) embedded into 2D carbon nanosheets, thus resulting in the formation 0D-1D-2D TiO $@ \mathrm{MoO}_{2} / \mathrm{C}$ hybrid composite. The tiny $\mathrm{MoO}_{2}$ nanoparticles were successfully grafted onto stable $\mathrm{TiO}_{2}$ nanowires to enhance specific capacity (Figs. 5(b) and 5(c)). In addition, external 2D carbon network can significantly avoid surface oxidation of $\mathrm{MoO}_{2}$ nanoparticles, maintaining the integrity of whole structure as well as high conductivity. Consequently, such a novel 0D-1D-2D nanoarchitecture demonstrated a high capacity and excellent cycling performance (Fig. 5(d)). Similar to hybrid composite mentioned above, Luo et al. [58] prepared a novel hierarchical hollow $\mathrm{TiO}_{2} @ \mathrm{Fe}_{2} \mathrm{O}_{3}$ core-shell nanoarrays (Fig. 5(e)). Firstly, high-density $\mathrm{Co}_{2}(\mathrm{OH})_{2} \mathrm{CO}_{3}$ nanowire array was uniformly prepared on $\mathrm{Ni}$ foam by a simple hydrothermal growth. Then, controllable $\mathrm{TiO}_{2}$ layer was directly deposited on the surface of as prepared $\mathrm{Co}_{2}(\mathrm{OH})_{2} \mathrm{CO}_{3}$ nanowire array by atomic layer deposition (ALD) method. In addition, $\mathrm{TiO}_{2}$-coated $\mathrm{Co}_{2}(\mathrm{OH})_{2} \mathrm{CO}_{3}$ nanowire array was immersed in $\mathrm{FeCl}_{3}$ solution through an ion-exchange-accelerated hydrolysis, thus leading to the formation of $\mathrm{FeOOH}$-coated $\mathrm{TiO}_{2}$ nanowire array. Eventually, hierarchical hollow $\mathrm{TiO}_{2} @ \mathrm{Fe}_{2} \mathrm{O}_{3}$ core-shell nanostructure can be obtained after annealing treatment. A typical TEM image of the as-fabricated nanoarrays is characterized in Fig. 5(f). External $\mathrm{Fe}_{2} \mathrm{O}_{3}$ nanospikes are uniformly attached to the hollow $\mathrm{TiO}_{2}$ nanowire. The robust hollow $\mathrm{TiO}_{2}$ nanowire serves as a stable substrate and provides a conductive path for electrons. As a result, such a hierarchical hollow structure exhibits a high reversible capacity and improved cycle stability (Fig. 5(g)), which maintained about $530 \mathrm{mAh} / \mathrm{g}$ after 200 cycles at the current density of $200 \mathrm{~mA} / \mathrm{g}$. Wang et al. [59] reported a simple strategy to fabricate a series of hierarchical heterostructures composed of $\mathrm{TiO}_{2}$ nanofiber substrate and $\mathrm{Co}_{3} \mathrm{O}_{4}$ nanosheets with the aid of the electrospinning technique and hydrothermal method as illustrated in Figs. 5(h) and 5(i). The synergistic effects of $\mathrm{TiO}_{2}$ nanofiber substrate and $\mathrm{Co}_{3} \mathrm{O}_{4}$ nanosheets were demonstrated in LIB performance, which deliver a 

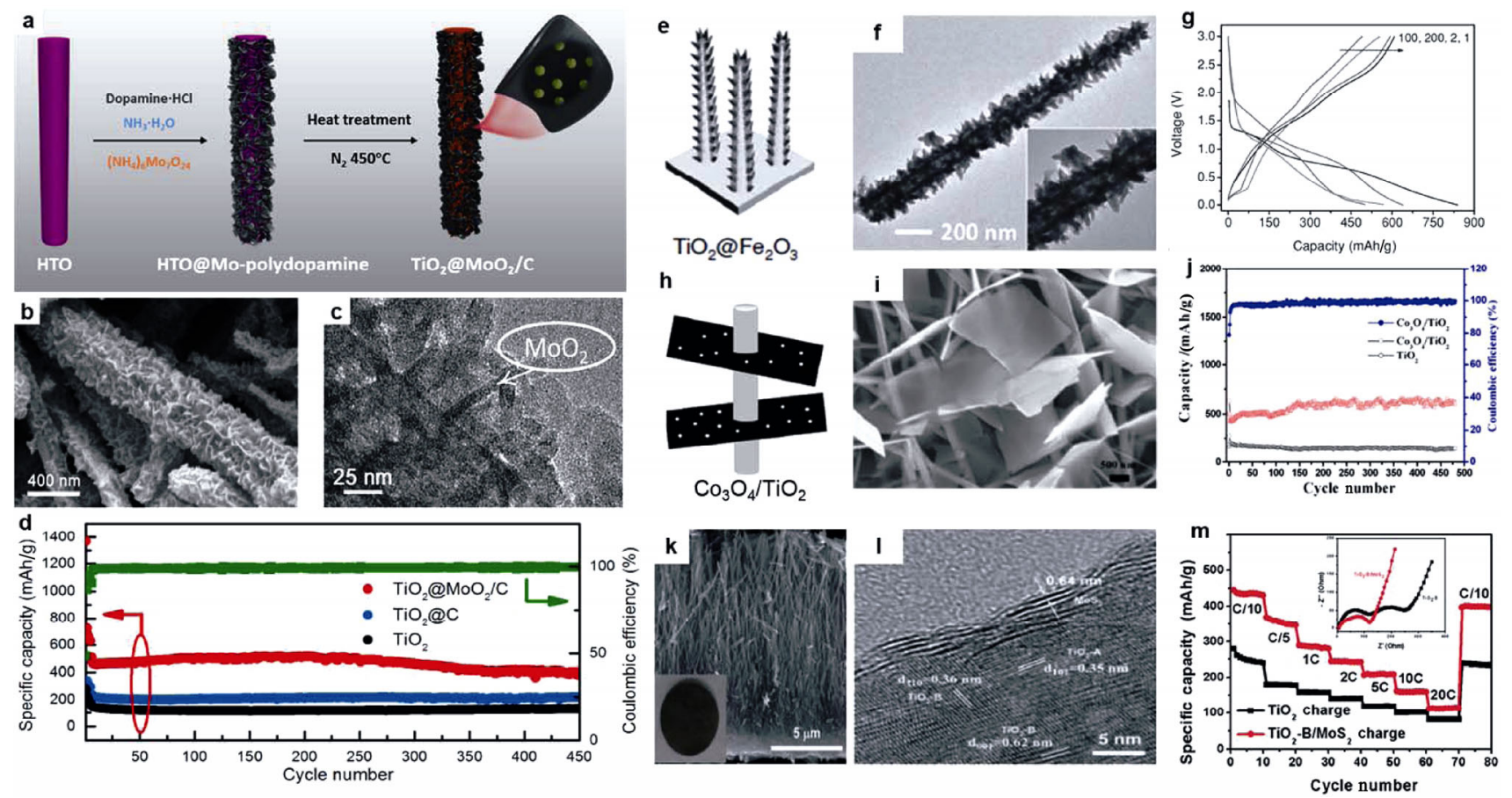

Fig. 5 Recent progress of $\mathrm{TiO}_{2}$ hybrid nanocomposites with conversion-type anodes. (a) Schematic of the synthetic process, (b) SEM image, (c) HRTEM image, and (d) cycling performance (at $500 \mathrm{~mA} / \mathrm{g}$ ) of $\mathrm{TiO}_{2} @ \mathrm{MoO}_{2} / \mathrm{C}$ nanocomposite. Reproduced with permission from Ref. [57], (C) American Chemical Society 2017. (e) Schematic model, (f) TEM image, and (g) galvanostatic discharge/charge profiles (at $200 \mathrm{~mA} / \mathrm{g}$ ) of $\mathrm{TiO}_{2} @ \mathrm{Fe}_{2} \mathrm{O}_{3}$ nanocomposites. Reproduced with permission from Ref. [58], C John Wiley and Sons 2013. (h) Schematic model, (i) SEM image, and (j) cycling performance (at $200 \mathrm{~mA} / \mathrm{g}$ ) of the $\mathrm{Co}_{3} \mathrm{O}_{4} / \mathrm{TiO}_{2}$ heterostructures. Reproduced with permission from Ref. [59], C Springer Nature 2012. (k) SEM image, (l) HRTEM image, and (m) rate performances of $\mathrm{TiO}_{2}-\mathrm{B} / \mathrm{MoS}_{2}$ nanowires. Reproduced with permission from Ref. [60], (C) The Royal Society of Chemistry 2016.

high reversible capacity, excellent cycling stability as well as excellent rate capability. The capacity of the as prepared sample can maintain a reversible capacity of $602.8 \mathrm{mAh} / \mathrm{g}$ even after 480 cycles (Fig. 5(j)). Except for transition metal oxides, transition metal sulfides also have attracted great attention because of their high theoretical specific capacity for lithium ion storage. Manthiram and coworkers [60] developed a facile strategy for $\mathrm{TiO}_{2}-\mathrm{B} / \mathrm{MoS}_{2}$ nanowire arrays, which directly grow on a current collector without any binder or carbon. The image of this structure is shown in Figs. 5(k) and $5(1)$; a core-shell structure composed of $\mathrm{TiO}_{2}-\mathrm{B}$ nanowires coated with a few $\mathrm{MoS}_{2}$ nanosheets can be seen. Such a special structure provides good cycling stability and excellent charge distribution with the help of $\mathrm{TiO}_{2}-\mathrm{B}$ nanowire array and highly ordered $\mathrm{MoS}_{2}$ nanosheets, leading to the enhancement of ion diffusion and charge transport kinetics. In addition, metallic 2D $\mathrm{MoS}_{2}$ layered structure favors high rate capability and the enhancement of the capacity because of its conversiontype reaction. As a result, the $\mathrm{TiO}_{2}-\mathrm{B} / \mathrm{MoS}_{2}$ hybrid electrode showed excellent rate performance (Fig. $5(\mathrm{~m})$ ) and long-term stability, which delivers a charge capacity of $350 \mathrm{mAh} / \mathrm{g}$ after 100 cycles. The present strategy could provide a novel method to fabricate 3D hybrid nanoarrays as high-performance additive-free electrodes for advanced lithium ion storage. What is more, more $\mathrm{TiO}_{2}$-based heterogeneous nanoachitectures with conversion-type anodes have been reported and listed in Table 1; due to the synergistic effects of stable substrate of $\mathrm{TiO}_{2}$, and high capacity of conversion-type anodes (such as $\mathrm{MoO}_{2}, \mathrm{MnO}_{2}, \mathrm{Fe}_{3} \mathrm{O}_{4}, \alpha-\mathrm{Fe}_{2} \mathrm{O}_{3}, \mathrm{NiFe}_{2} \mathrm{O}_{4}$, $\mathrm{Co}_{3} \mathrm{O}_{4}, \mathrm{MoS}_{2}, \mathrm{FeS}$ ), the capacity of the hybrid composites can be greatly enhanced up to $820 \mathrm{mAh} / \mathrm{g}$ (after 1000 cycles at $500 \mathrm{~mA} / \mathrm{g}$ ).

Besides $\mathrm{TiO}_{2}, \mathrm{Li}_{4} \mathrm{Ti}_{5} \mathrm{O}_{12}$ has also been used as the "zero-strain" substrate for high capacity materials. Our group developed a novel $3 \mathrm{D} \mathrm{Li} 4 \mathrm{Ti}_{5} \mathrm{O}_{12}-\mathrm{TiO}_{2} / \mathrm{MoO}_{2}$ core/ shell porous superstructure coated by carbon nanosheets for boosting more efficient lithium ion storage [61]. Figure 6(a) is the procedure to fabricate 3D hierarchical structure, including the formation of the hydrated lithium titanium precursor (LHTO-NWs), followed by depositing with the 2D hybrid nanosheets, and finally in situ 
Table 1 Comparison of the electrochemical performances of Ti-based hybrid nanocomposites with conversion-type anodes. Their electrode compositions are listed using the mass ratio of active materials: conductive carbon: binder

\begin{tabular}{|c|c|c|c|c|}
\hline Electrode material & $\begin{array}{c}\text { Electrode } \\
\text { composition }\end{array}$ & $\begin{array}{l}\text { Loading density } \\
\left(\mathrm{mg} / \mathrm{cm}^{2}\right)\end{array}$ & Capacity after cycles (current density) & Ref. \\
\hline $\mathrm{TiO}_{2} @ \mathrm{MoO}_{2} / \mathrm{C}$ heterostructures & $80: 10: 10$ & $\sim 1.0$ & 400,450 cycles $(500 \mathrm{~mA} / \mathrm{g})$ & {$[57]$} \\
\hline $\mathrm{MoO}_{2}$-modified $\mathrm{TiO}_{2}$ nanofibers & $80: 10: 10$ & N/A & $514.5,50$ cycles $(0.2 \mathrm{C})$ & {$[64]$} \\
\hline $\mathrm{TiO}_{2}-\mathrm{C} / \mathrm{MnO}_{2}$ core-double-shell nanowire arrays & $100: 0: 0$ & 1.5 & 218,150 cycles $(3350 \mathrm{~mA} / \mathrm{g})$ & {$[65]$} \\
\hline Core/shell $\mathrm{TiO}_{2}-\mathrm{MnO}_{2} / \mathrm{MnO}_{2}$ heterostructures & $80: 10: 10$ & $\mathrm{~N} / \mathrm{A}$ & 185,500 cycles $(2000 \mathrm{~mA} / \mathrm{g})$ & {$[66]$} \\
\hline $\mathrm{Fe}_{3} \mathrm{O}_{4}-\mathrm{TiO}_{2}$-carbon hierarchical nanofibrous & $80: 10: 10$ & $1-2$ & 525,100 cycles $(100 \mathrm{~mA} / \mathrm{g})$ & {$[67]$} \\
\hline $\mathrm{TiO}_{2} / \mathrm{Fe}_{3} \mathrm{O}_{4}-\mathrm{PG}$ ternary heterostructures & $70: 20: 10$ & N/A & 524,200 cycles $(1000 \mathrm{~mA} / \mathrm{g})$ & {$[68]$} \\
\hline $\mathrm{TiO}_{2} @ \alpha-\mathrm{Fe}_{2} \mathrm{O}_{3}$ core-shell nanostructures & 100:0:0 & $\sim 0.6$ & 820,1000 cycles $(500 \mathrm{~mA} / \mathrm{g})$ & {$[69]$} \\
\hline $\mathrm{TiO}_{2} @ \mathrm{Fe}_{2} \mathrm{O}_{3}$ hollow nanostructures & 100:0:0 & N/A & 530,200 cycles $(200 \mathrm{~mA} / \mathrm{g})$ & {$[58]$} \\
\hline $\mathrm{Co}_{3} \mathrm{O}_{4} / \mathrm{TiO}_{2}$ hierarchical heterostructures & $70: 20: 10$ & N/A & $602.8,480$ cycles $(200 \mathrm{~mA} / \mathrm{g})$ & {$[59]$} \\
\hline Core-shell $\mathrm{NiFe}_{2} \mathrm{O}_{4} @ \mathrm{TiO}_{2}$ nanorods & $70: 20: 10$ & $\mathrm{~N} / \mathrm{A}$ & 321,100 cycles $(100 \mathrm{~mA} / \mathrm{g})$ & {$[70]$} \\
\hline $\mathrm{TiO}_{2}-\mathrm{B} / \mathrm{MoS}_{2}$ nanowire arrays & 100:0:0 & 1.2 & 350,100 cycles $(20 \mathrm{~mA} / \mathrm{g})$ & {$[60]$} \\
\hline $\mathrm{FeS} @ \mathrm{TiO}_{2}$ nanostructures & $70: 20: 10$ & N/A & 430,500 cycles $(400 \mathrm{~mA} / \mathrm{g})$ & {$[71]$} \\
\hline $\mathrm{Li}_{4} \mathrm{Ti}_{5} \mathrm{O}_{12}-\mathrm{TiO}_{2} @ \mathrm{MoO}_{2} / \mathrm{C}$ 3D heterostructures & $80: 10: 10$ & $\sim 1.0$ & 413,500 cycles $(1000 \mathrm{~mA} / \mathrm{g})$ & {$[61]$} \\
\hline $\mathrm{Li}_{4} \mathrm{Ti}_{5} \mathrm{O}_{12} / \mathrm{NiO}$ nanocomposites & $80: 10: 10$ & $\mathrm{~N} / \mathrm{A}$ & 176,100 cycles $(1 \mathrm{C})$ & {$[72]$} \\
\hline $\mathrm{Li}_{4} \mathrm{Ti}_{5} \mathrm{O}_{12} / \mathrm{Co}_{3} \mathrm{O}_{4}$ composites & $80: 10: 10$ & N/A & $\sim 300,50$ cycles $(160 \mathrm{~mA} / \mathrm{g})$ & {$[73]$} \\
\hline$\alpha-\mathrm{Fe}_{2} \mathrm{O}_{3} @ \mathrm{Li}_{4} \mathrm{Ti}_{5} \mathrm{O}_{12}$ heterostructures & $80: 10: 10$ & $\mathrm{~N} / \mathrm{A}$ & 249,30 cycles $(100 \mathrm{~mA} / \mathrm{g})$ & {$[74]$} \\
\hline $\mathrm{Li}_{4} \mathrm{Ti}_{5} \mathrm{O}_{12} / \mathrm{MoS}_{2}$ heterostructures & $80: 10: 10$ & $0.9-1.8$ & $\sim 160,1000$ cycles $(10 \mathrm{C})$ & [62] \\
\hline
\end{tabular}
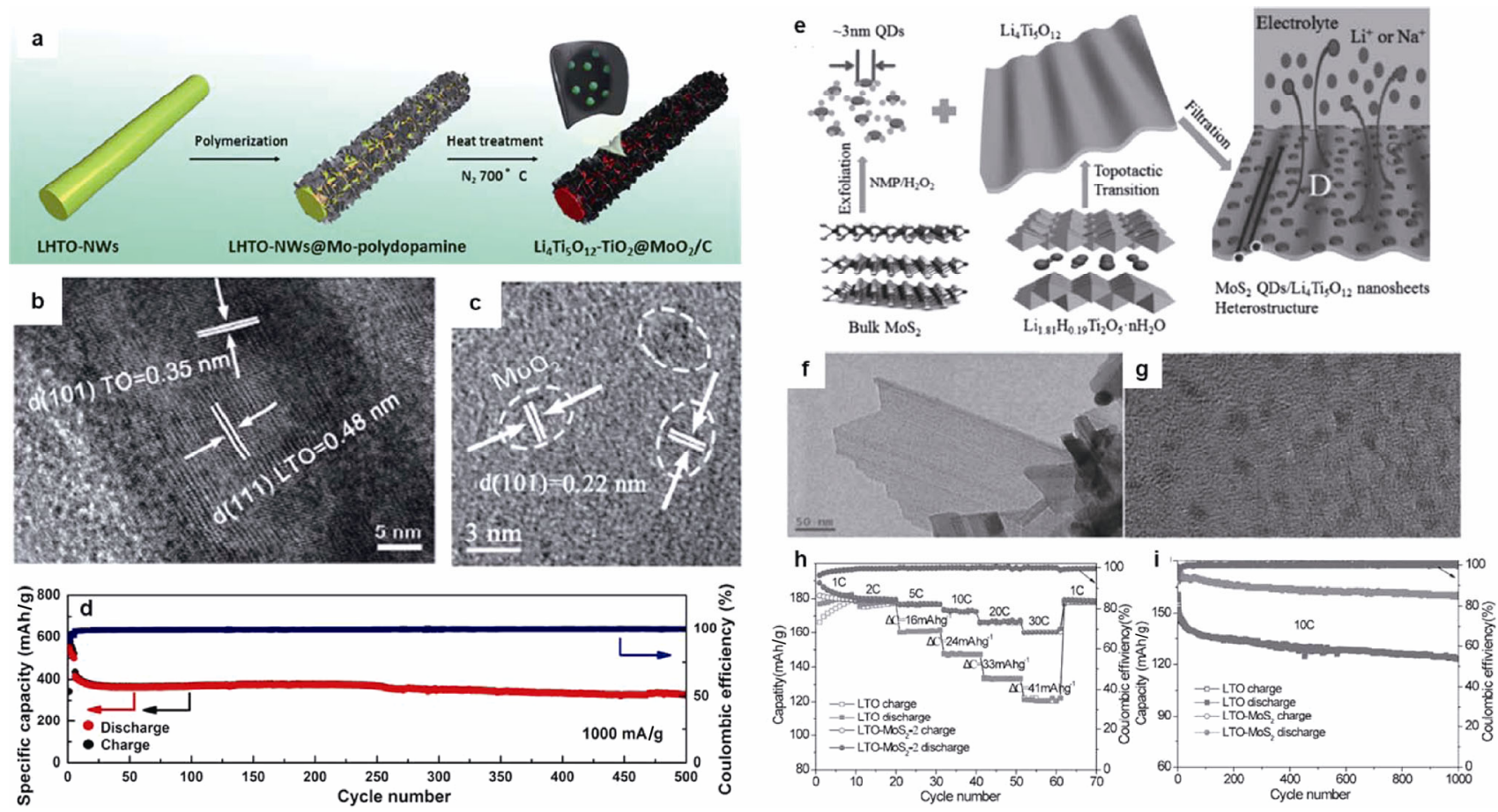

Fig. 6 Recent progress of $\mathrm{Li}_{4} \mathrm{Ti}_{5} \mathrm{O}_{12}$ hybrid nanocomposites with conversion-type anodes. (a) Schematic preparation process, (b, c) HRTEM images, and (d) cycling performance of $\mathrm{Li}_{4} \mathrm{Ti}_{5} \mathrm{O}_{12}-\mathrm{TiO}_{2} @ \mathrm{MoO}_{2} / \mathrm{C}$ nanocomposite. Reproduced with permission from Ref. [61], (c) The Royal Society of Chemistry 2017. (e) Schematic preparation process, (f, g) HRTEM images, (h) rate performance, and (i) cycling performances of $\mathrm{MoS}_{2} \mathrm{QDs} / \mathrm{Li}_{4} \mathrm{Ti}_{5} \mathrm{O}_{12}$ nanosheet nanostructure. Reproduced with permission from Ref. [62], (c) John Wiley and Sons 2016.

generating $\mathrm{MoO}_{2}$ nanoclusters encapsulated in carbon nanosheets. As showed in Figs. 6(b) and 6(c), numerous tiny $\mathrm{MoO}_{2}$ nanoclusters can be detected after the carbonization treatment. Taking advantage of highcapacity $\mathrm{MoO}_{2}$ nanoclusters and high-stability $\mathrm{Li}_{4} \mathrm{Ti}_{5} \mathrm{O}_{12}-$ $\mathrm{TiO}_{2}$ nanorods, as well as high-conductivity carbon 
nanosheets, the capacity of $\mathrm{Li}_{4} \mathrm{Ti}_{5} \mathrm{O}_{12}-\mathrm{TiO}_{2}$ nanorods has been enhanced to $627.8 \mathrm{mAh} / \mathrm{g}$ at $100 \mathrm{~mA} / \mathrm{g}$ and simultaneously maintains the stability of Ti-based substrate for 500 cycles with a capacity fade of $0.04 \%$ per cycle (Fig. 6(d)). Further investigation showed that the presence of tiny $\mathrm{MoO}_{2}$ in carbon nanosheets allows to significantly enhance the specific capacity. What is more, encapsulating $\mathrm{MoO}_{2}$ nanoclusters is also beneficial for improving the electrical conductivity and the pseudocapacitive behavior. In this sense, rational designing hierarchical superstructures as well as strongly coupled interaction with the carbon matrix is pretty important for boosting lithium ion storage.

The Ti-based substrate we mentioned above is 1D nanowires or arrays, and 2D nanosheets have received great attention due to their larger specific surface area and unique physical and chemical properties. It was reported that some unprecedented electrochemical effects occur on the surface of 2D nanostructure, leading to fast ion diffusion and numerous ion insertion channels [49,50, 63]. In this respect, the combination of $2 \mathrm{D}$ nanosheets as the stable substrate, is well suited for capacity enhancement of Ti-based materials. Very recently, $\mathrm{Xu}$ et al. [62] reported a novel $0 \mathrm{D} / 2 \mathrm{D}$ hetero-structure assembled by ultrathin $\mathrm{Li}_{4} \mathrm{Ti}_{5} \mathrm{O}_{12}$ nanosheets and ultrasmall $\mathrm{MoS}_{2}$ quantum dots (QDs). In a typical synthesis, the vacuum-filtration assisted assembly process was employed to combine ultrathin $\mathrm{Li}_{4} \mathrm{Ti}_{5} \mathrm{O}_{12}$ nanosheets and ultrasmall $\mathrm{MoS}_{2}$ QDs (Fig. 6(e)). It was accepted that QDs composed of tens of atoms possess pretty high surface-to-mass ratio. Combined with $2 \mathrm{D}$ ultrathin $\mathrm{Li}_{4} \mathrm{Ti}_{5} \mathrm{O}_{12}$ nanosheets, numerous $\mathrm{MoS}_{2}$ QDs can be homogeneously anchored on the surface of $\mathrm{Li}_{4} \mathrm{Ti}_{5} \mathrm{O}_{12}$ nanosheets (Figs. 6(f) and $6(\mathrm{~g})$ ), boosting the electrochemical properties. The resulting $0 \mathrm{D} / 2 \mathrm{D}$ hetero-structure showed enhanced surface-controlled $\mathrm{Li}$ storage behaviors. As anode material in LIBs, the hybrid composite exhibited enhanced capacity and high-rate capability as well as superior cycling performance, a high specific capacity about $161 \mathrm{mAh} / \mathrm{g}$ can be achieved at a high rate of $30 \mathrm{C}$ and the capacity can maintain $94.1 \%$ after 1000 fast cycling at $10 \mathrm{C}$ (Figs. 6(d) and 6(e)). Finally, $\mathrm{Li}_{4} \mathrm{Ti}_{5} \mathrm{O}_{12}$-based hierarchical nanoachitectures with conversion-type anodes have been reported and listed in Table 1; due to the synergistic effects of stable substrate of $\mathrm{Li}_{4} \mathrm{Ti}_{5} \mathrm{O}_{12}$, and high capacity of conversion- type anodes (such as $\mathrm{MoO}_{2}$, $\mathrm{NiO}, \mathrm{Co}_{3} \mathrm{O}_{4}, \alpha-\mathrm{Fe}_{2} \mathrm{O}_{3}, \mathrm{MoS}_{2}$ ), the capacity of the hybrid composites can be greatly enhanced up to 413 $\mathrm{mAh} / \mathrm{g}$ (after 500 cycles at $1000 \mathrm{~mA} / \mathrm{g}$ ).

\section{2 Alloying-type hybrid nanocomposites}

In this subsection, the alloying-type of hybrid composites to enhance capacity will be briefly emphasized in terms of the structure manipulation and hierarchical configurations, and subsequently improved electrochemical performances will be discussed and compared.

Among the various Li alloy elements, silicon and its compounds have been considered as one of the most attractive anode materials for LIBs because it has the highest specific capacity $(4200 \mathrm{mAh} / \mathrm{g})$. However, a major drawback is the rapid capacity fading due to the huge mechanical expansion strain caused by the large volume expansion/contraction during $\mathrm{Li}$ insertion/ extraction. Li et al. [75] developed a novel watermelonlike structured $\mathrm{SiO}_{x}-\mathrm{TiO}_{2} @ \mathrm{C}$ nanocomposite. Ultra-small $\mathrm{TiO}_{2}$ nanocrystals are uniformly encapsulated inside $\mathrm{SiO}_{x}$ particles, forming unique $\mathrm{SiO}_{x}-\mathrm{TiO}_{2}$ dual-phase cores. As showed in Fig. 7(a), the addition of $\mathrm{TiO}_{2}$ component can significantly enhance the electronic and lithium ionic conductivity and meanwhile release the structural stress caused by alloying/dealloying of $\mathrm{Si}$ compounds. In addition, the outer carbon coating shell can not only endow high electronic conduction of active materials, but also alleviate the mechanical stress generated by the large volume change of Si component. Accordingly, under the current density of $0.1 \mathrm{~A} / \mathrm{g}$, a high specific capacity of $910 \mathrm{mAh} / \mathrm{g}$ is retained after 200 cycles, and $700 \mathrm{mAh} / \mathrm{g}$ can be maintained after 200 cycles even the high current density of $1 \mathrm{~A} / \mathrm{g}$ (Figs. 7(b) and 7(c)).

Besides $\mathrm{Si}$, metallic tin ( $\mathrm{Sn})$ as well as its oxides have been proved as the promising anode materials for nextgeneration LIBs due to their high theoretical capacity (991 mAh/g for $\mathrm{Sn} ; \sim 790 \mathrm{mAh} / \mathrm{g}$ for $\mathrm{SnO}_{2}$ ) [76]. The basic reaction mechanisms of $\mathrm{SnO}_{2}$ and $\mathrm{Sn}$ materials have been illustrated as follows. In the first lithiation process, $\mathrm{SnO}_{2}$ is converted to $\mathrm{Sn}$ via an irreversible conversion-type reaction (Eq. (3)). Then, the alloying/ dealloying reactions of the in situ formed Sn phase would happen in the subsequent cycling (Eq. (4)). Accordingly, the formation of $\mathrm{Li}_{4.4} \mathrm{Sn}$ results in the large volume expansion ( $300 \%)$.

$$
\begin{gathered}
\mathrm{SnO}_{2}+4 \mathrm{Li}^{+}+4 \mathrm{e}^{-} \Leftrightarrow \mathrm{Sn}+2 \mathrm{Li}_{2} \mathrm{O} \\
\mathrm{Sn}+x \mathrm{Li}^{+}+x \mathrm{e}^{-} \Leftrightarrow \mathrm{Li}_{x} \mathrm{Sn}(0 \leqslant x \leqslant 4.4)
\end{gathered}
$$

In attempts to accommodate the volume change during discharge/charge processes and to improve the first 


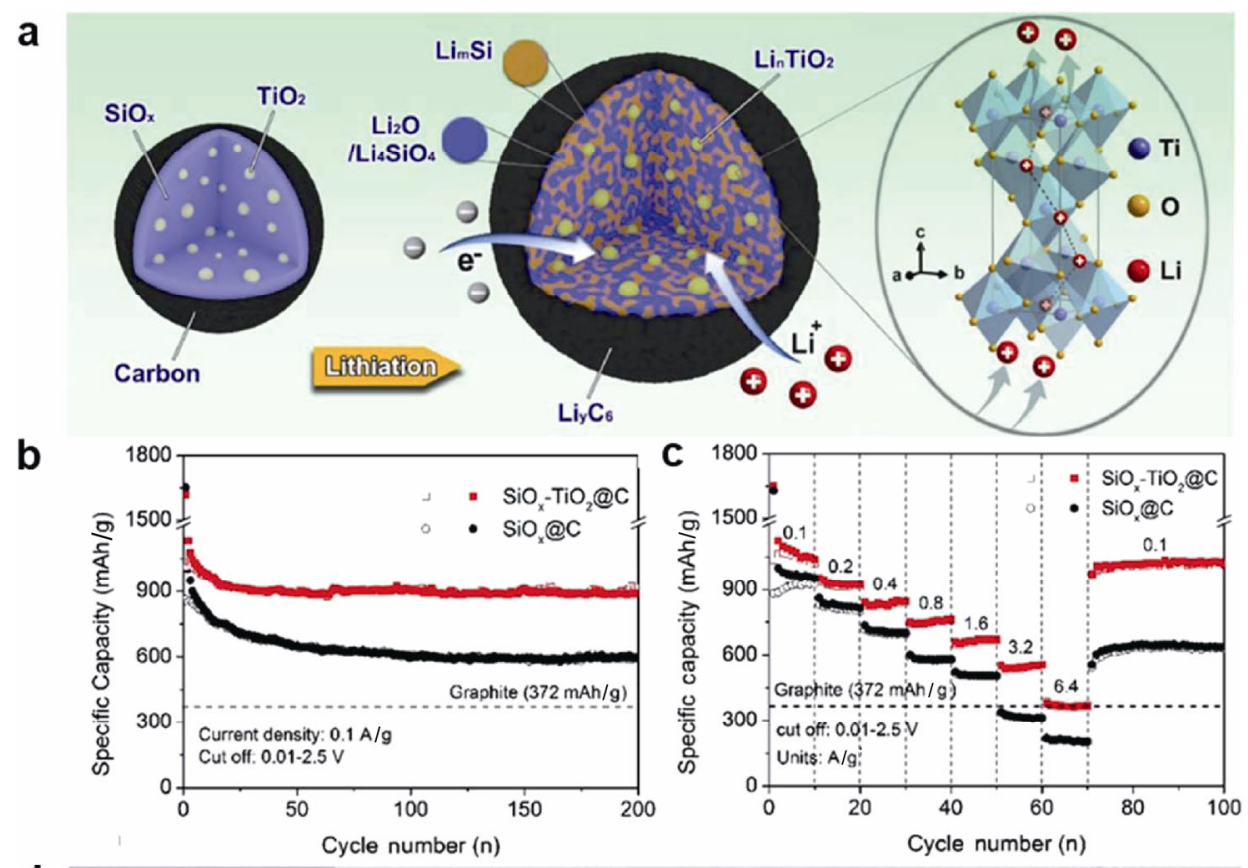

d

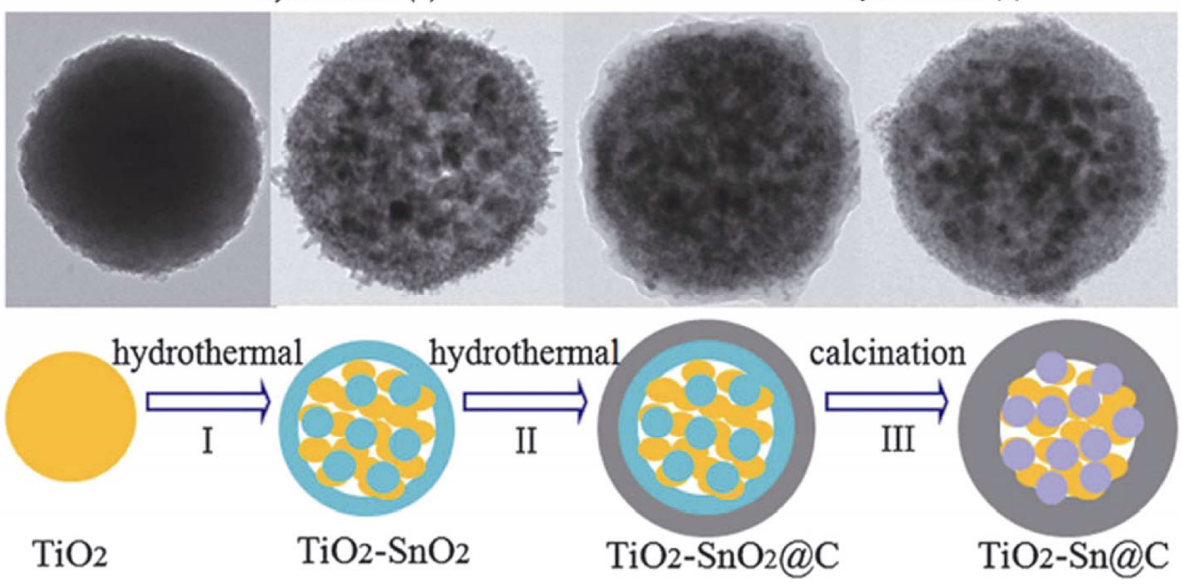

Fig. 7 Recent progress of $\mathrm{TiO}_{2}$ hybrid nanocomposites with alloying-type anodes. (a) Schematic illustration for first lithiation process and $(b, c)$ electrochemical performances of watermelon-like structured $\mathrm{SiO}_{x}-\mathrm{TiO}_{2} @ \mathrm{C}$ nanoparticle. Reproduced with permission from Ref. [75], (C) John Wiley and Sons 2018. (d) Schematic illustration and TEM images of the fabrication process of $\mathrm{TiO}_{2}-\mathrm{Sn} @ \mathrm{C}$ core-shell microspheres. Reproduced with permission from Ref. [78], (c) The Royal Society of Chemistry 2013.

Coulombic efficiency and cycle performance, various architectures regarding material structure rather than pure nanoparticle have been designed and proved. Hollow nanostructure allows accommodating volume expansion and alleviating the expansion stress, thus enabling superior cycling stability compared to the nanoparticles. $\mathrm{Wu}$ and coworkers [77] reported a self-templated strategy to fabricate hierarchical $\mathrm{TiO}_{2} / \mathrm{SnO}_{2}$ hollow spheres coated with graphitized carbon (HTSO/GC-HSs). Combining sol-gel process and calcination treatment, a robust mesoporous hollow structure composed of ultrafine solid solution of rutile $\mathrm{TiO}_{2}$ and $\mathrm{SnO}_{2}$ and anatase $\mathrm{TiO}_{2}$ embedded in carbon was successfully obtained. The as-prepared mesoporous HTSO/GC-HSs with high specific area exhibit an interesting yolk- double-shell structure, which manifests exceptional cycling stability and rate performance for LIBs. In this case, a high reversible specific capacity of about $310 \mathrm{mAh} / \mathrm{g}$ can be maintained after 500 cycles even at a high current density of $5 \mathrm{~A} / \mathrm{g}$. Therefore, rationally constructing well-defined hollow architecture can achieve exceptional cycling stability and rate performance. Chen et al. [78] developed a novel mesoporous $\mathrm{TiO}_{2}-\mathrm{Sn} @ \mathrm{C}$ core-shell microspheres by several hydrothermal methods, as illustrated Fig. 7(d). In this work, Sn nanoparticles were successfully encapsulated into a $\mathrm{TiO}_{2}$ matrix coated with a carbon layer. As a result, the mesoporous $\mathrm{TiO}_{2}$ matrix and the carbon shell can prevent the aggregation 
of Sn, buffer volume change, and accommodate structural stress of Sn during electrochemical processes. The as-prepared $\mathrm{TiO}_{2}-\mathrm{Sn} @ \mathrm{C}$ composite exhibits excellent long-term cycling stability, which exhibited a reversible capacity of $206.2 \mathrm{mAh} / \mathrm{g}$ at $500 \mathrm{~mA} / \mathrm{g}$ after 2000 cycles. Liao and Manthiram [79] developed 3D mesoporous $\mathrm{TiO}_{2}-\mathrm{Sn} / \mathrm{C}$ core-shell nanowire arrays on $\mathrm{Ti}$ foil as anodes for lithium-ion batteries. Such a core-shell nanowire array structure can effectively buffer the volume change, suppress cracking, and improve the conductivity of the electrode during the discharge-charge process, thus resulting in superior rate capability and excellent long-term cycling stability. The as-prepared $\mathrm{TiO}_{2}-\mathrm{Sn} / \mathrm{C}$ nanowire arrays exhibit a capacity retention rate of $84.8 \%$ with a discharge capacity of over $160 \mathrm{mAh} / \mathrm{g}$, even after 100 cycles at a high current rate of $10 \mathrm{C}$.

Similar to $\mathrm{TiO}_{2}, \mathrm{Li}_{4} \mathrm{Ti}_{5} \mathrm{O}_{12}-\mathrm{SnO}_{2}$ hybrid composite also exhibits enhanced electrochemical performance. As mentioned above, Sn-based compounds still suffer from huge volume change during the process of lithiation/delithiation, hence giving rise to poor cycling performance. Cai et al. [80] developed $\mathrm{Li}_{4} \mathrm{Ti}_{5} \mathrm{O}_{12}-\mathrm{Sn}$ oxide composites by introducing various amounts of $\mathrm{SnO}_{2}$ nanostructure. It was found that $\mathrm{Sn}$ oxide was uniformly encapsulated on the surface of the $\mathrm{Li}_{4} \mathrm{Ti}_{5} \mathrm{O}_{12}$ material. The as-obtained sample delivered an outstanding capacity retention of $224 \mathrm{mAh} / \mathrm{g}$ after 50 cycles at a current rate of $100 \mathrm{~mA} / \mathrm{g}$. In addition, Han et al. [81] prepared a hybrid composed of $2 \mathrm{D} \mathrm{Li}_{4} \mathrm{Ti}_{5} \mathrm{O}_{12}$ nanosheets and $0 \mathrm{D} \mathrm{SnO}_{2}$ nanocrystals via the second crystal growth method. The immobilization of $\mathrm{SnO}_{2}$ nanocrystals on the surface of $\mathrm{Li}_{4} \mathrm{Ti}_{5} \mathrm{O}_{12} 2 \mathrm{D}$ nanosheets provides strong interaction between different components. Owing to the synergistic effect, the as-obtained composite exhibited improved LIBs performance compared to pure $\mathrm{Li}_{4} \mathrm{Ti}_{5} \mathrm{O}_{12}$ nanosheets and $\mathrm{SnO}_{2}$ nanoparticles. Very recently, our group developed a simple second growth method to prepare $\mathrm{Li}_{4} \mathrm{Ti}_{5} \mathrm{O}_{12}-\mathrm{TiO}_{2} / \mathrm{Sn}$ nanowire composite [82]. The detailed fabrication process of the $\mathrm{Li}_{4} \mathrm{Ti}_{5} \mathrm{O}_{12}-\mathrm{TiO}_{2} / \mathrm{Sn}$ nanowires coated by $\mathrm{N}$-doped carbon can be seen in Figs. 8(a) and 8(b). In this work, combining the robust $\mathrm{Li}_{4} \mathrm{Ti}_{5} \mathrm{O}_{12}-\mathrm{TiO}_{2}$ core substrates and high capacity of $\mathrm{Sn}$ nanoparticles, the as-prepared sample exhibited enhanced capacity for boosting lithium ion storage. Importantly, the N-doped carbon coating endows to improve electrical conductivity and ion permeability as well as stability [83]. As a result, the novel nanocomposites show an initial discharge capacity of $964 \mathrm{mAh} / \mathrm{g}$ and a capacity retention of about $360 \mathrm{mAh} / \mathrm{g}$ after 600 cycles at a high current rate of $1000 \mathrm{mAg}$ in Fig. 8(c), which is benefit for high capacity anode material in LIBs. It was proposed that this hierarchal architecture could provide better lithium ion storage by providing more accommodation so as to ease its large volume changes. In addition, the presence of 1D substrate can provide rapid electrical pathways for efficient charge transport, leading to the high specific capacity and long cycling stability.

To reduce the $\mathrm{Li}^{+}$diffusion length and to increase the tolerance to strains during alloying/dealloying process, fabricating rational structures such as hollow architecture or core-shell structure are highly desirable, which witness a great success in Si-based anodes [11-14]. Ji et al. [84] designed a hollow core/shell structure to improve the lithium ion storage by $\mathrm{Li}_{4} \mathrm{Ti}_{5} \mathrm{O}_{12}$ surface coating. In a typical synthesis, $\mathrm{SnO}_{2} @ \mathrm{TiO}_{2}$ could be obtained via a simple hydrothermal method, followed by coating $\mathrm{TiO}_{2}$ by the hydrolysis rate of titanium isopropoxide. Finally, $\mathrm{TiO}_{2}$ shell can be converted into $\mathrm{Li}_{4} \mathrm{Ti}_{5} \mathrm{O}_{12}$ shell after lithium hydroxide reaction, generating the formation of $\mathrm{SnO}_{2} @ \mathrm{Li}_{4} \mathrm{Ti}_{5} \mathrm{O}_{12}$ core/shell composites (Fig. 8(d)). In this work, well-defined hollow architecture with porosity in the shell allows to ease the strain during charging/discharging. What is more, the external $\mathrm{Li}_{4} \mathrm{Ti}_{5} \mathrm{O}_{12}$ coating can significantly reduce the initial irreversible capacity loss (due to stable SEI) and to enhance the capacity and cyclability of $\mathrm{SnO}_{2}$. Finally, Table 2 summarizes the recent work about Ti-based composites with alloying-type anodes; due to the synergistic effects of stable substrate of $\mathrm{TiO}_{2}$ and $\mathrm{Li}_{4} \mathrm{Ti}_{5} \mathrm{O}_{12}$, and high capacity of alloying-type anodes (such as $\mathrm{SiO}_{x}, \mathrm{Sn}, \mathrm{SnO}_{2}$ ), the capacity of the hybrid composites can be greatly enhanced up to $700 \mathrm{mAh} / \mathrm{g}$ (after 600 cycles at $1000 \mathrm{~mA} / \mathrm{g}$ ).

\section{Conclusions and perspectives}

Ti-based materials can be regarded as promising anode materials in energy storage and conversion field due to their amazing safety and excellent rate capability. In this review, the aim is to give a summary about the enhancement of Ti-based compounds with low specific capacity. We start with a brief recent progress of Ti-based compounds, including the use of nanostructuring, surface coating as well as hierarchical hybridization with carbon and so on. Most of the advanced Ti-based 
a

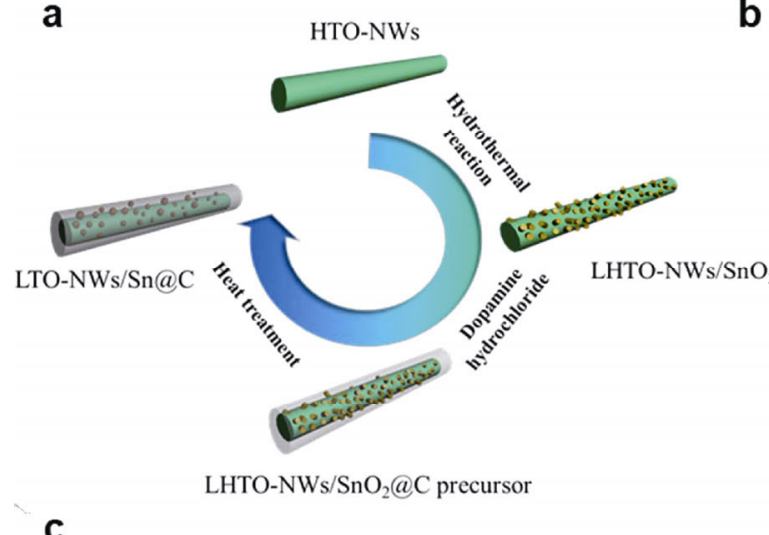

b

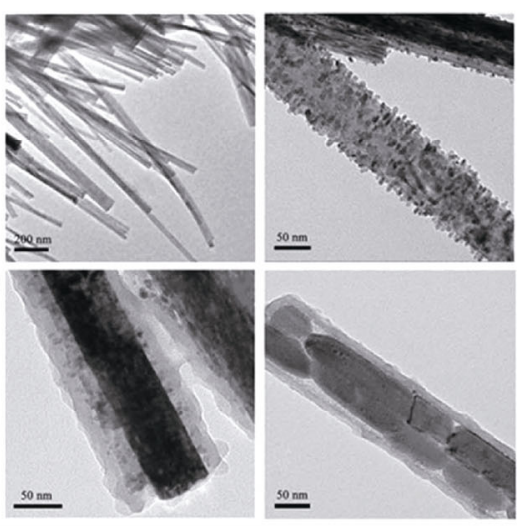

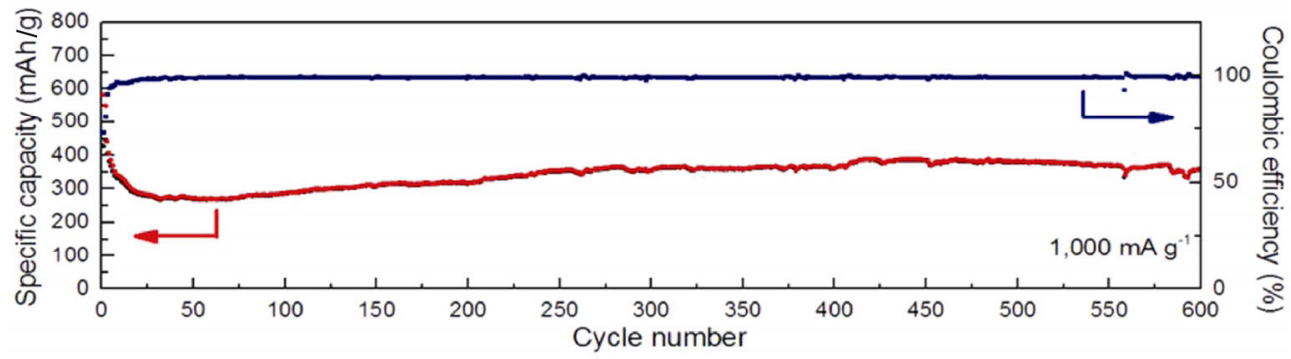

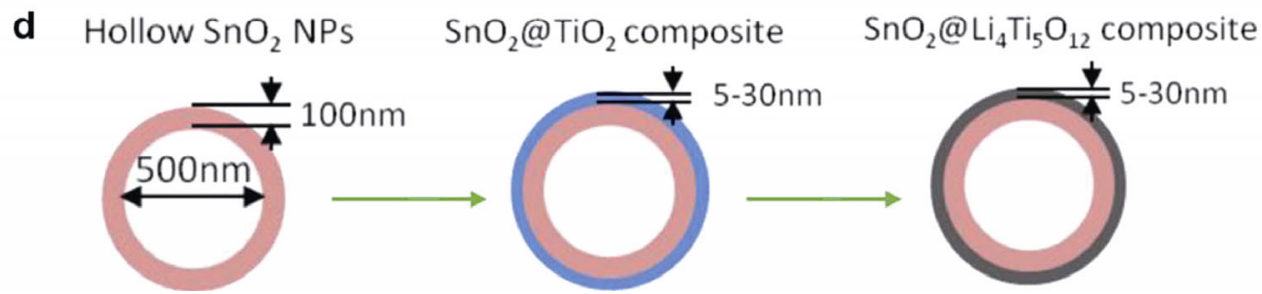

Fig. 8 Recent progress of $\mathrm{Li}_{4} \mathrm{Ti}_{5} \mathrm{O}_{12}$ hybrid nanocomposites with alloying-type anodes. (a) Schematic illustration, (b) TEM images of the fabrication process of $\mathrm{Li}_{4} \mathrm{Ti}_{5} \mathrm{O}_{12}-\mathrm{TiO}_{2} / \mathrm{Sn}$ nanowires, and (c) cycling performances of $\mathrm{Li}_{4} \mathrm{Ti}_{5} \mathrm{O}_{12}-\mathrm{TiO}_{2} / \mathrm{Sn}$ composite. Reproduced with permission from Ref. [82], (C) The Royal Society of Chemistry 2016. (d) Schematic illustration of the fabrication process of $\mathrm{SnO}_{2} @ \mathrm{Li}_{4} \mathrm{Ti}_{5} \mathrm{O}_{12}$ nanocomposite. Reproduced with permission from Ref. [84], (C) American Chemical Society 2012.

Table 2 Comparison of the electrochemical performances of Ti-based hybrid nanocomposites with alloying-type anodes. Their electrode compositions are listed using the mass ratio of active materials: conductive carbon: binder

\begin{tabular}{|c|c|c|c|c|}
\hline Electrode material & $\begin{array}{l}\text { Electrode } \\
\text { composition }\end{array}$ & $\begin{array}{l}\text { Loading density } \\
\qquad\left(\mathrm{mg} / \mathrm{cm}^{2}\right)\end{array}$ & Capacity after cycles (current density) & Ref. \\
\hline Watermelon-like $\mathrm{SiO}_{x}-\mathrm{TiO}_{2} @ \mathrm{C}$ nanocomposite & $75: 15: 15$ & 1.3 & $\sim 700,600$ cycles $(1000 \mathrm{~mA} / \mathrm{g})$ & [75] \\
\hline $\mathrm{TiO}_{2} / \mathrm{SnO}_{2}$ hollow spheres & $80: 10: 10$ & $0.4-1.0$ & 310,600 cycles $(5000 \mathrm{~mA} / \mathrm{g})$ & [77] \\
\hline $\mathrm{TiO}_{2}-\mathrm{Sn} / \mathrm{C}$ core-shell nanowires arrays & 100:0:0 & $\sim 1.0$ & 459,160 cycles $(335 \mathrm{~mA} / \mathrm{g})$ & [79] \\
\hline $\mathrm{TiO}_{2}-\mathrm{Sn} @ \mathrm{C}$ core-shell microspheres & $80: 10: 10$ & N/A & 206,2000 cycles $(500 \mathrm{~mA} / \mathrm{g})$ & [78] \\
\hline $\mathrm{SnO}_{2} @ \mathrm{Li}_{4} \mathrm{Ti}_{5} \mathrm{O}_{12}$ & $80: 10: 10$ & N/A & 457,30 cycles $(100 \mathrm{~mA} / \mathrm{g})$ & [84] \\
\hline $\mathrm{SnO}_{2} @ \mathrm{TiO}_{2} @$ reduced graphene oxide nanotubes & $80: 10: 10$ & $\sim 2.0$ & $\sim 700,70$ cycles $(500 \mathrm{~mA} / \mathrm{g})$ & [85] \\
\hline $\mathrm{SnO}_{2} / \mathrm{TiO}_{2}$ nanocomposite & $60: 20: 20$ & N/A & $\sim 600,100$ cycles $(0.2 \mathrm{C})$ & [86] \\
\hline $\mathrm{SnO}_{2} @ \mathrm{TiO}_{2}$ double-shell nanotubes & $70: 10: 20$ & N/A & 200,50 cycles $(1500 \mathrm{~mA} / \mathrm{g})$ & [87] \\
\hline $\mathrm{TiO}_{2}(\mathrm{~B}) @ \mathrm{SnO}_{2}$ carbon nanowires & $75: 15: 15$ & N/A & 669,67 cycles $(60 \mathrm{~mA} / \mathrm{g})$ & [88] \\
\hline N-doped carbon coated $\mathrm{Li}_{4} \mathrm{Ti}_{5} \mathrm{O}_{12}-\mathrm{TiO}_{2} / \mathrm{Sn}$ nanowires & $80: 10: 10$ & $1.0-1.2$ & 360,600 cycles $(1000 \mathrm{~mA} / \mathrm{g})$ & [82] \\
\hline $\mathrm{Li}_{4} \mathrm{Ti}_{5} \mathrm{O}_{12} / \mathrm{Sn}$ nanocomposite & $80: 10: 10$ & N/A & 200,30 cycles $(0.02 \mathrm{C})$ & [89] \\
\hline $\mathrm{Li}_{4} \mathrm{Ti}_{5} \mathrm{O}_{12} /$ tin composite & $85: 9: 8$ & N/A & 224,50 cycles $(100 \mathrm{~mA} / \mathrm{g})$ & [80] \\
\hline $\mathrm{Li}_{4} \mathrm{Ti}_{5} \mathrm{O}_{12} 2 \mathrm{D}$ nanosheets and $\mathrm{SnO}_{2}$ 0D nanocrystals & $80: 10: 10$ & N/A & 150,30 cycles $\left(0.1 \mathrm{~mA} / \mathrm{cm}^{2}\right)$ & [81] \\
\hline
\end{tabular}


materials can exhibit notable cycling performances with $<10^{-3} \%$ capacity loss per cycle; however, the energy density enhancement is still limited due to the relatively low theoretical specific capacity. We highlight the synthetic protocol and advantages of Ti-based heterogeneous architectures with conversion-/alloyingtype hybrid. Owing to the synergistic effects of highly stable substrate of Ti-based materials, high-capacity feature of conversion-/alloying-type anodes, as well as conductivity and structural stability enhancement with some carbonaceous networks, the capacities of Ti-based materials have been improved obviously and effectively. However, a number of challenges remain unresolved in the development of Ti-based anode materials for LIBs to meet the growing application criteria.

(1) For most of the conversion-type anodes, the redox potential is quite wide $\left(0-3 \mathrm{~V} v \mathrm{vs} . \mathrm{Li} / \mathrm{Li}^{+}\right)$which results in lower output voltage when assembling full battery compared with graphite $\left(\sim 0.1 \mathrm{~V}\right.$ vs. $\left.\mathrm{Li}^{-} \mathrm{Li}^{+}\right)$. This will sacrifice the power density of the battery system. By contrast, the potential of alloying-type anode (e.g., Si: $\sim 0.4 \mathrm{~V}$; Sn: $0.4-0.8 \mathrm{~V}$; Al: $\sim 0.4 \mathrm{~V}$ vs. $\left.\mathrm{Li} / \mathrm{Li}^{+}\right)$is much lower than conversion-type anodes. Therefore, we believe alloying-type anodes are more practical and competitive when considering battery devices in real-life applications.

(2) Note that for Ti-based materials, the structure during cycling is super-stable but the capacity is low; whereas for high-capacity materials like conversion-/ alloying-type anode, the capacity is very high but the structural stability is poor. Therefore, the wise protocol to improve the capacity of Ti-based materials sometimes is the good choice to enhance the stability of conversion-/ alloying-type anode. In this case, we think (i) the 0D-1D-2D heterogeneous nanoarchitectures with 0D high-capacity nanoparticles, 1D stable Ti-based material, and 2D conductive carbon network (coating), and (ii) core-shell micro-nano spheres with high-capacity material as the core and structural stable Ti-based materials as the protective shell are very promising synthetic strategy to obtain ideal high-capacity and long-life anodes for LIBs.

(3) Take into account practical production or industrialization, facile strategies with low production costs are urgently essential. The competitive electrode materials should meet the requirement of available production line. It is well known that reliability and homogeneity of heterogeneous nanocomposites are still the biggest challenges for their large-scale production.
To overcome this issue, the joint efforts are highly appreciated, not only for the breakthrough in the fields of electrochemistry, physical chemistry, solid state/ polymer chemistry as well as surficial and interface science, but also for the collaborations among the fields of academic, manufacturing industry, and battery industry.

In a word, we are optimistic that Ti-based materials with rational designs and structure manipulation could have great potentials and a bright future for the nextgeneration energy storage.

\section{Acknowledgements}

This work was financially supported by the National Natural Science Foundation of China (Nos. 51472137 and 51772163).

\section{References}

[1] Choi JW, Aurbach D. Promise and reality of post-lithium-ion batteries with high energy densities. Nat Rev Mater 2016, 1: 16013.

[2] Chen Z, Belharouak I, Sun Y-K, et al. Titanium-based anode materials for safe lithium-ion batteries. Adv Funct Mater 2013, 23: 959-969.

[3] Yang Z, Choi D, Kerisit S, et al. Nanostructures and lithium electrochemical reactivity of lithium titanites and titanium oxides: A review. J Power Sources 2009, 192: 588-598.

[4] Wang S, Quan W, Zhu Z, et al. Lithium titanate hydrates with superfast and stable cycling in lithium ion batteries. Nat Commun 2017, 8: 627.

[5] Zhao B, Ran R, Liu M, et al. A comprehensive review of $\mathrm{Li}_{4} \mathrm{Ti}_{5} \mathrm{O}_{12}$-based electrodes for lithium-ion batteries: The latest advancements and future perspectives. Mat Sci Eng $R$ 2015, 98: 1-71.

[6] Yi T-F, Yang S-Y, Xie Y. Recent advances of $\mathrm{Li}_{4} \mathrm{Ti}_{5} \mathrm{O}_{12}$ as a promising next generation anode material for high power lithium-ion batteries. J Mater Chem A 2015, 3: 5750-5777.

[7] Zhu G-N, Wang Y-G, Xia Y-Y. Ti-based compounds as anode materials for Li-ion batteries. Energy Environ Sci 2012, 5: 6652-6667.

[8] Yuan T, Tan Z, Ma C, et al. Challenges of spinel $\mathrm{Li}_{4} \mathrm{Ti}_{5} \mathrm{O}_{12}$ for lithium-ion battery industrial applications. Adv Energy Mater 2017, 7: 1601625.

[9] Reddy MV, Subba Rao GV, Chowdari BVR. Metal oxides and oxysalts as anode materials for $\mathrm{Li}$ ion batteries. Chem Rev 2013, 113: 5364-5457.

[10] Ji L, Lin Z, Alcoutlabi M, et al. Recent developments in nanostructured anode materials for rechargeable lithium-ion batteries. Energy Environ Sci 2011, 4: 2682-2699. 
[11] Obrovac MN, Chevrier VL. Alloy negative electrodes for Li-ion batteries. Chem Rev 2014, 114: 11444-11502.

[12] Aravindan V, Lee Y-S, Madhavi S. Research progress on negative electrodes for practical Li-ion batteries: Beyond carbonaceous anodes. Adv Energy Mater 2015, 5: 1402225.

[13] Zuo X, Zhu J, Müller-Buschbaum P, et al. Silicon based lithium-ion battery anodes: A chronicle perspective review. Nano Energy 2017, 31: 113-143.

[14] Zhang W-J. A review of the electrochemical performance of alloy anodes for lithium-ion batteries. J Power Sources 2011, 196: 13-24.

[15] Hong Z, Wei M. Layered titanate nanostructures and their derivatives as negative electrode materials for lithium-ion batteries. J Mater Chem A 2013, 1: 4403-4414.

[16] Chiu H-C, Lu X, Zhou J, et al. Capacity fade mechanism of $\mathrm{Li}_{4} \mathrm{Ti}_{5} \mathrm{O}_{12}$ nanosheet anode. Adv Energy Mater 2017, 7: 1601825.

[17] Zhou W, Liu H, Boughton RI, et al. One-dimensional single-crystalline Ti-O based nanostructures: Properties, synthesis, modifications and applications. J Mater Chem 2010, 20: 5993-6008.

[18] Deng D, Kim MG, Lee JY, et al. Green energy storage materials: Nanostructured $\mathrm{TiO}_{2}$ and Sn-based anodes for lithium-ion batteries. Energy Environ Sci 2009, 2: 818-837.

[19] Hua X, Liu Z, Fischer MG, et al. Lithiation thermodynamics and kinetics of the $\mathrm{TiO}_{2}(\mathrm{~B})$ nanoparticles. $J$ Am Chem Soc 2017, 139: 13330-13341.

[20] Li J, Wan W, Zhou H, et al. Hydrothermal synthesis of $\mathrm{TiO}_{2}(\mathrm{~B})$ nanowires with ultrahigh surface area and their fast charging and discharging properties in Li-ion batteries. Chem Commun 2011, 47: 3439-3441.

[21] Liu H, Bi Z, Sun X-G, et al. Mesoporous $\mathrm{TiO}_{2}-\mathrm{B}$ microspheres with superior rate performance for lithium ion batteries. Adv Mater 2011, 23: 3450-3454.

[22] Tang Y, Zhang Y, Deng J, et al. Mechanical force-driven growth of elongated bending $\mathrm{TiO}_{2}$-based nanotubular materials for ultrafast rechargeable lithium ion batteries. Adv Mater 2014, 26: 6111-6118.

[23] Tang Y, Zhang Y, Deng J, et al. Unravelling the correlation between the aspect ratio of nanotubular structures and their electrochemical performance to achieve high-rate and long-life lithium-ion batteries. Angew Chem Int Edit 2014, 53: 13488-13492.

[24] Liu S, Wang Z, Yu C, et al. A flexible $\mathrm{TiO}_{2}(\mathrm{~B})$-based battery electrode with superior power rate and ultralong cycle life. Adv Mater 2013, 25: 3462-3467.

[25] Ren G, Hoque MNF, Liu J, et al. Perpendicular edge oriented graphene foam supporting orthogonal $\mathrm{TiO}_{2}(\mathrm{~B})$ nanosheets as freestanding electrode for lithium ion battery. Nano Energy 2016, 21: 162-171.

[26] Guan BY, Yu L, Li J, et al. A universal cooperative assembly-directed method for coating of mesoporous $\mathrm{TiO}_{2}$ nanoshells with enhanced lithium storage properties. Sci Adv 2016, 2: e1501554.

[27] Wei H, Rodriguez EF, Hollenkamp AF, et al. High reversible pseudocapacity in mesoporous yolk-shell anatase $\mathrm{TiO}_{2} / \mathrm{TiO}_{2}(\mathrm{~B})$ microspheres used as anodes for Li-ion batteries. Adv Funct Mater 2017, 27: 1703270.

[28] Naldoni A, Allieta M, Santangelo S, et al. Effect of nature and location of defects on bandgap narrowing in black $\mathrm{TiO}_{2}$ nanoparticles. J Am Chem Soc 2012, 134: 7600-7603.

[29] Xia T, Zhang W, Li W, et al. Hydrogenated surface disorder enhances lithium ion battery performance. Nano Energy 2013, 2: 826-835.

[30] Liu H, Li W, Shen D, et al. Graphitic carbon conformal coating of mesoporous $\mathrm{TiO}_{2}$ hollow spheres for high-performance lithium ion battery anodes. $J \mathrm{Am}$ Chem Soc 2015, 137: 13161-13166.

[31] Zhao L, Wang S, Pan F, et al. Thermal convection induced $\mathrm{TiO}_{2}$ microclews as superior electrode materials for lithium-ion batteries. J Mater Chem A 2018, 6: 11688-11693.

[32] Lee GH, Lee JW, Choi JIL, et al. Ultrafast discharge/charge rate and robust cycle life for high-performance energy storage using ultrafine nanocrystals on the binder-free porous graphene foam. Adv Funct Mater 2016, 26: 5139-5148.

[33] Wang H, Jia G, Guo Y, et al. Atomic layer deposition of amorphous $\mathrm{TiO}_{2}$ on carbon nanotube networks and their superior $\mathrm{Li}$ and $\mathrm{Na}$ ion storage properties. Adv Mater Interfaces 2016, 3: 1600375.

[34] Sun L, Kong W, Wu H, et al. Mesoporous $\mathrm{Li}_{4} \mathrm{Ti}_{5} \mathrm{O}_{12}$ nanoclusters anchored on super-aligned carbon nanotubes as high performance electrodes for lithium ion batteries. Nanoscale 2016, 8: 617-625.

[35] Mao S, Huang X, Chang J, et al. One-step, continuous synthesis of a spherical $\mathrm{Li}_{4} \mathrm{Ti}_{5} \mathrm{O}_{12}$ graphene composite as an ultra-long cycle life lithium-ion battery anode. $N P G$ Asia Materials 2015, 7: e224-e224.

[36] Borghols WJH, Wagemaker M, Lafont U, et al. Size effects in the $\mathrm{Li}_{4+x} \mathrm{Ti}_{5} \mathrm{O}_{12}$ spinel. $J$ Am Chem Soc 2009, 131: 17786-17792.

[37] Ohzuku T, Ueda A, Yamamoto N. Zero-strain insertion material of $\mathrm{Li}\left[\mathrm{Li}_{1 / 3} \mathrm{Ti}_{5 / 3}\right] \mathrm{O}_{4}$ for rechargeable lithium cells. $J$ Electrochem Soc 1995, 142: 1431-1435.

[38] Haetge J, Hartmann P, Brezesinski K, et al. Ordered large-pore mesoporous $\mathrm{Li}_{4} \mathrm{Ti}_{5} \mathrm{O}_{12}$ spinel thin film electrodes with nanocrystalline framework for high rate rechargeable lithium batteries: Relationships among charge storage, electrical conductivity, and nanoscale structure. Chem Mater 2011, 23: 4384-4393.

[39] $\mathrm{He}$ Y, Muhetaer A, Li J, et al. Ultrathin $\mathrm{Li}_{4} \mathrm{Ti}_{5} \mathrm{O}_{12}$ nanosheet based hierarchical microspheres for high-rate and long-cycle life Li-ion batteries. Adv Energy Mater 2017, 7: 1700950.

[40] Wang C, Wang S, He Y-B, et al. Combining fast Li-ion battery cycling with large volumetric energy density: Grain boundary induced high electronic and ionic conductivity in $\mathrm{Li}_{4} \mathrm{Ti}_{5} \mathrm{O}_{12}$ spheres of densely packed nanocrystallites. Chem Mater 2015, 27: 5647-5656.

[41] Ge $\mathrm{H}$, Cui L, Sun $\mathrm{Z}$, et al. Unique $\mathrm{Li}_{4} \mathrm{Ti}_{5} \mathrm{O}_{12} / \mathrm{TiO}_{2}$ multilayer arrays with advanced surface lithium storage capability. J Mater Chem A 2018, 6: 22053-22061. 
[42] Wang S, Yang Y, Quan W, et al. $\mathrm{Ti}^{3+}$-free three-phase $\mathrm{Li}_{4} \mathrm{Ti}_{5} \mathrm{O}_{12} / \mathrm{TiO}_{2}$ for high-rate lithium ion batteries: Capacity and conductivity enhancement by phase boundaries. Nano Energy 2017, 32: 294-301.

[43] Shen L, Zhang X, Uchaker E, et al. $\mathrm{Li}_{4} \mathrm{Ti}_{5} \mathrm{O}_{12}$ nanoparticles embedded in a mesoporous carbon matrix as a superior anode material for high rate lithium ion batteries. $A d v$ Energy Mater 2012, 2: 691-698.

[44] Yao Z, Xia X, Zhou C, et al. Smart construction of integrated $\mathrm{CNTs} / \mathrm{Li}_{4} \mathrm{Ti}_{5} \mathrm{O}_{12}$ core/shell arrays with superior high-rate performance for application in lithium-ion batteries. Adv Sci 2018, 5: 1700786.

[45] Tang Y, Zhang Y, Rui X, et al. Conductive inks based on a lithium titanate nanotube gel for high-rate lithium-ion batteries with customized configuration. Adv Mater 2016, 28: $1567-1576$.

[46] Wang Y-Q, Gu L, Guo Y-G, et al. Rutile- $\mathrm{TiO}_{2}$ nanocoating for a high-rate $\mathrm{Li}_{4} \mathrm{Ti}_{5} \mathrm{O}_{12}$ anode of a lithium-ion battery. $J$ Am Chem Soc 2012, 134: 7874-7879.

[47] Zhou C, Xia X, Wang Y, et al. Pine-needle-like $\mathrm{Cu}-\mathrm{Co}$ skeleton composited with $\mathrm{Li}_{4} \mathrm{Ti}_{5} \mathrm{O}_{12}$ forming core-branch arrays for high-rate lithium ion storage. Small 2018, 14: 1704339.

[48] Goriparti S, Miele E, De Angelis F, et al. Review on recent progress of nanostructured anode materials for Li-ion batteries. J Power Sources 2014, 257: 421-443.

[49] Mei J, Liao T, Kou L, et al. Two-dimensional metal oxide nanomaterials for next-generation rechargeable batteries. Adv Mater 2017, 29: 1700176.

[50] Liu J, Liu X-W. Two-dimensional nanoarchitectures for lithium storage. Adv Mater 2012, 24: 4097-4111.

[51] Devan RS, Patil RA, Lin J-H, et al. One-dimensional metal-oxide nanostructures: Recent developments in synthesis, characterization, and applications. Adv Funct Mater 2012, 22: 3326-3370.

[52] Wang Z, Zhou L, Lou XW. Metal oxide hollow nanostructures for lithium-ion batteries. Adv Mater 2012, 24: 1903-1911.

[53] Mohana Reddy AL, Gowda SR, Shaijumon MM, et al. Hybrid nanostructures for energy storage applications. $A d v$ Mater 2012, 24: 5045-5064.

[54] Kim MG, Cho J. Reversible and high-capacity nanostructured electrode materials for Li-ion batteries. Adv Funct Mater 2009, 19: 1497-1514.

[55] Jiang J, Li Y, Liu J, et al. Recent advances in metal oxide-based electrode architecture design for electrochemical energy storage. Adv Mater 2012, 24: 5166-5180.

[56] Palacin MR. Recent advances in rechargeable battery materials: A chemist's perspective. Chem Soc Rev 2009, 38: 2565-2575.

[57] Wang S, Zhang Z, Yang Y, et al. Efficient lithium-ion storage by hierarchical core-shell $\mathrm{TiO}_{2}$ nanowires decorated with $\mathrm{MoO}_{2}$ quantum dots encapsulated in carbon nanosheets. ACS Appl Mater Interfaces 2017, 9: 23741-23747.

[58] Luo J, Xia X, Luo Y, et al. Rationally designed hierarchical $\mathrm{TiO}_{2} @ \mathrm{Fe}_{2} \mathrm{O}_{3}$ hollow nanostructures for improved lithium ion storage. Adv Energy Mater 2013, 3: 737-743.

[59] Wang H, Ma D, Huang X, et al. General and controllable synthesis strategy of metal oxide $/ \mathrm{TiO}_{2}$ hierarchical heterostructures with improved lithium-ion battery performance. Sci Rep 2012, 2: 701.

[60] Liao J-Y, Luna BD, Manthiram A. $\mathrm{TiO}_{2}-\mathrm{B}$ nanowire arrays coated with layered $\mathrm{MoS}_{2}$ nanosheets for lithium and sodium storage. J Mater Chem A 2016, 4: 801-806.

[61] Yang Y, Wang S, Luo M, et al. $\mathrm{Li}_{4} \mathrm{Ti}_{5} \mathrm{O}_{12}-\mathrm{TiO}_{2} / \mathrm{MoO}_{2}$ nanoclusters-embedded into carbon nanosheets core/shell porous superstructures boost lithium ion storage. J Mater Chem A 2017, 5: 12096-12102.

[62] Xu G, Yang L, Wei X, et al. $\mathrm{MoS}_{2}$-quantum-dot-interspersed $\mathrm{Li}_{4} \mathrm{Ti}_{5} \mathrm{O}_{12}$ nanosheets with enhanced performance for $\mathrm{Li}-$ and Na-ion batteries. Adv Funct Mater 2016, 26: 3349 3358.

[63] Wang L, Sasaki T. Titanium oxide nanosheets: Graphene analogues with versatile functionalities. Chem Rev 2014, 114: 9455-9486.

[64] Luo $\mathrm{W}, \mathrm{Hu} \mathrm{X}$, Sun $\mathrm{Y}$, et al. Surface modification of electrospun $\mathrm{TiO}_{2}$ nanofibers via layer-by-layer self-assembly for high-performance lithium-ion batteries. J Mater Chem 2012, 22: 4910-4915.

[65] Liao J-Y, Higgins D, Lui G, et al. Multifunctional $\mathrm{TiO}_{2}-\mathrm{C} / \mathrm{MnO}_{2}$ core-double-shell nanowire arrays as high-performance 3D electrodes for lithium ion batteries. Nano Lett 2013, 13: 5467-5473.

[66] Li X, Chen Y, Yao H, et al. Core/shell $\mathrm{TiO}_{2}-\mathrm{MnO}_{2} / \mathrm{MnO}_{2}$ heterostructure anodes for high-performance lithium-ion batteries. RSC Adv 2014, 4: 39906-39911.

[67] Li S, Wang M, Luo Y, et al. Bio-inspired hierarchical nanofibrous $\mathrm{Fe}_{3} \mathrm{O}_{4}-\mathrm{TiO}_{2}$-carbon composite as a high-performance anode material for lithium-ion batteries. ACS Appl Mater Interfaces 2016, 8: 17343-17351.

[68] Pan L, Zhu X-D, Xie X-M, et al. Smart hybridization of $\mathrm{TiO}_{2}$ nanorods and $\mathrm{Fe}_{3} \mathrm{O}_{4}$ nanoparticles with pristine graphene nanosheets: Hierarchically nanoengineered ternary heterostructures for high-rate lithium storage. Adv Funct Mater 2015, 25: 3341-3350.

[69] Yang J, Wu Q, Yang X, et al. Chestnut-like $\mathrm{TiO}_{2} @ \alpha-\mathrm{Fe}_{2} \mathrm{O}_{3}$ core-shell nanostructures with abundant interfaces for efficient and ultralong life lithium-ion storage. ACS Appl Mater Interfaces 2017, 9: 354-361.

[70] Huang G, Zhang F, Du X, et al. Core-shell $\mathrm{NiFe}_{2} \mathrm{O}_{4} @ \mathrm{TiO}_{2}$ nanorods: An anode material with enhanced electrochemical performance for lithium-ion batteries. Chem Eur J 2014, 20 : 11214-11219.

[71] Wang X, Xiang Q, Liu B, et al. $\mathrm{TiO}_{2}$ modified FeS nanostructures with enhanced electrochemical performance for lithium-ion batteries. Sci Rep 2013, 3: 2007.

[72] Zhang C, Shao D, Gao Q, et al. Electrochemical lithium storage of $\mathrm{Li}_{4} \mathrm{Ti}_{5} \mathrm{O}_{12} / \mathrm{NiO}$ nanocomposites for high-performance lithium-ion battery anodes. J Solid State Electrochem 2015, 19: 1859-1866.

[73] Hong J-E, Oh R-G, Ryu K-S. $\mathrm{Li}_{4} \mathrm{Ti}_{5} \mathrm{O}_{12} / \mathrm{Co}_{3} \mathrm{O}_{4}$ composite 
for improved performance in lithium-ion batteries. $J$ Electrochem Soc 2015, 162: A1978-A1983.

[74] Chen M, Li W, Shen X, et al. Fabrication of core-shell $\alpha-\mathrm{Fe}_{2} \mathrm{O}_{3} @ \mathrm{Li}_{4} \mathrm{Ti}_{5} \mathrm{O}_{12}$ composite and its application in the lithium ion batteries. ACS Appl Mater Interfaces 2014, 6: 4514-4523.

[75] Li Z, Zhao H, Lv P, et al. Watermelon-like structured $\mathrm{SiO}_{x}-$ $\mathrm{TiO}_{2} @ \mathrm{C}$ nanocomposite as a high-performance lithium-ion battery anode. Adv Funct Mater 2018, 28: 1605711.

[76] Chen JS, Lou XW. $\mathrm{SnO}_{2}$-based nanomaterials: Synthesis and application in lithium-ion batteries. Small 2013, 9: 1877-1893.

[77] Xie H, Chen $\mathrm{M}$, Wu L. Hierarchical $\mathrm{TiO}_{2} / \mathrm{SnO}_{2}$ hollow spheres coated with graphitized carbon for high-performance electrochemical Li-ion storage. Small 2017, 13: 1604283.

[78] Chen J, Yang L, Zhang Z, et al. Mesoporous $\mathrm{TiO}_{2}-\mathrm{Sn} @ \mathrm{C}$ core-shell microspheres for Li-ion batteries. Chem Commun 2013, 49: 2792-2794.

[79] Liao J-Y, Manthiram A. Mesoporous $\mathrm{TiO}_{2}-\mathrm{Sn} / \mathrm{C}$ core-shell nanowire arrays as high-performance $3 \mathrm{D}$ anodes for Li-ion batteries. Adv Energy Mater 2014, 4: 1400403.

[80] Cai R, Yu X, Liu X, et al. $\mathrm{Li}_{4} \mathrm{Ti}_{5} \mathrm{O}_{12} / \mathrm{Sn}$ composite anodes for lithium-ion batteries: Synthesis and electrochemical performance. J Power Sources 2010, 195: 8244-8250.

[81] Han SY, Kim IY, Lee SH, et al. Electrochemically active nanocomposites of $\mathrm{Li}_{4} \mathrm{Ti}_{5} \mathrm{O}_{12} 2 \mathrm{D}$ nanosheets and $\mathrm{SnO}_{2} 0 \mathrm{D}$ nanocrystals with improved electrode performance. Electrochim Acta 2012, 74: 59-64.

[82] Wang S, Yang Y, Jiang C, et al. Nitrogen-doped carbon coated $\mathrm{Li}_{4} \mathrm{Ti}_{5} \mathrm{O}_{12}-\mathrm{TiO}_{2} / \mathrm{Sn}$ nanowires and their enhanced electrochemical properties for lithium ion batteries. $J$ Mater Chem A 2016, 4: 12714-12719.

[83] Yang Y, Wang S, Lin S, et al. Rational design of hierarchical $\mathrm{TiO}_{2}$ /epitaxially aligned $\mathrm{MoS}_{2}$-carbon coupled interface nanosheets core/shell architecture for ultrastable sodium ion and lithium-sulfur batteries. Small 2018, 2: 1800119.
[84] Ji G, Ma Y, Ding B, et al. Improving the performance of high capacity Li-ion anode materials by lithium titanate surface coating. Chem Mater 2012, 24: 3329-3334.

[85] Cheong JY, Kim C, Jang JS, et al. Rational design of Sn-based multicomponent anodes for high performance lithium-ion batteries: $\mathrm{SnO}_{2} @ \mathrm{TiO}_{2} @$ reduced graphene oxide nanotubes. RSC Adv 2016, 6: 2920-2925.

[86] Lin Y-M, Nagarale RK, Klavetter $\mathrm{KC}$, et al. $\mathrm{SnO}_{2}$ and $\mathrm{TiO}_{2}$-supported-SnO $\mathrm{Sn}_{2}$ lithium battery anodes with improved electrochemical performance. J Mater Chem 2012, 22: 11134-11139.

[87] Jeun J-H, Park K-Y, Kim D-H, et al. $\mathrm{SnO}_{2} @ \mathrm{TiO}_{2}$ double-shell nanotubes for a lithium ion battery anode with excellent high rate cyclability. Nanoscale 2013, 5: 8480-8483.

[88] Yang Z, Du G, Guo Z, et al. Encapsulation of $\mathrm{TiO}_{2}(\mathrm{~B})$ nanowire cores into $\mathrm{SnO}_{2}$ /carbon nanoparticle shells and their high performance in lithium storage. Nanoscale 2011, 3: $4440-4447$.

[89] Sivashanmugam A, Gopukumar S, Thirunakaran R, et al. Novel $\mathrm{Li}_{4} \mathrm{Ti}_{5} \mathrm{O}_{12} / \mathrm{Sn}$ nano-composites as anode material for lithium ion batteries. Mater Res Bull 2011, 46: 492-500.

Open Access This article is licensed under a Creative Commons Attribution 4.0 International License, which permits use, sharing, adaptation, distribution and reproduction in any medium or format, as long as you give appropriate credit to the original author(s) and the source, provide a link to the Creative Commons licence, and indicate if changes were made.

The images or other third party material in this article are included in the article's Creative Commons licence, unless indicated otherwise in a credit line to the material. If material is not included in the article's Creative Commons licence and your intended use is not permitted by statutory regulation or exceeds the permitted use, you will need to obtain permission directly from the copyright holder.

To view a copy of this licence, visit http://creativecommons. org/licenses/by/4.0/. 